NASA Contractor Report 4120

\title{
An Analytical Method \\ for Ditching Analysis of an Airborne Vehicle
}

\author{
Farhad Ghaffari \\ Vigyan Research Associates, Inc. \\ Hampton, Virginia
}

Prepared for

Langley Research Center

under Contract NAS1-17919

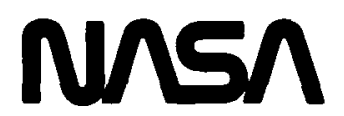

National Aeronautics

and Space Administration

Scientific and Technical Information Division 


\section{TABLE OF CONTENTS}

\section{INTRODUCTION.}

DITCHING METHOD AND EVALdATION........................... 3

Test Case Configuration.............................. 4

Free Surface Modeling.$\ldots \ldots \ldots \ldots \ldots \ldots \ldots \ldots \ldots \ldots \ldots \ldots \ldots \ldots \ldots \ldots \ldots$

Trailing Wake Modeling $\ldots \ldots \ldots \ldots \ldots \ldots \ldots \ldots \ldots \ldots \ldots \ldots \ldots \ldots \ldots \ldots$

Density Correction.................................... 6

Results and Discussions.............................. 8

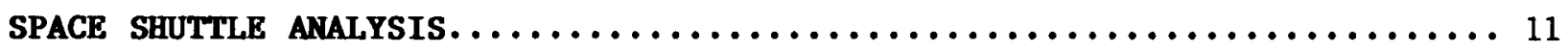

Geometry Preparation................................ 11

Free Air Evaluation................................. 14

Ditching Application................................. 15

CONCLUDING REMARKS $\ldots \ldots \ldots \ldots \ldots \ldots \ldots \ldots \ldots \ldots \ldots \ldots \ldots \ldots \ldots \ldots \ldots \ldots \ldots \ldots$

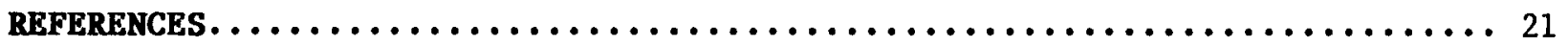

HFECEDING PAGE ELAIVi NOT FILN:O 


\section{Symbols and Abbreviations}

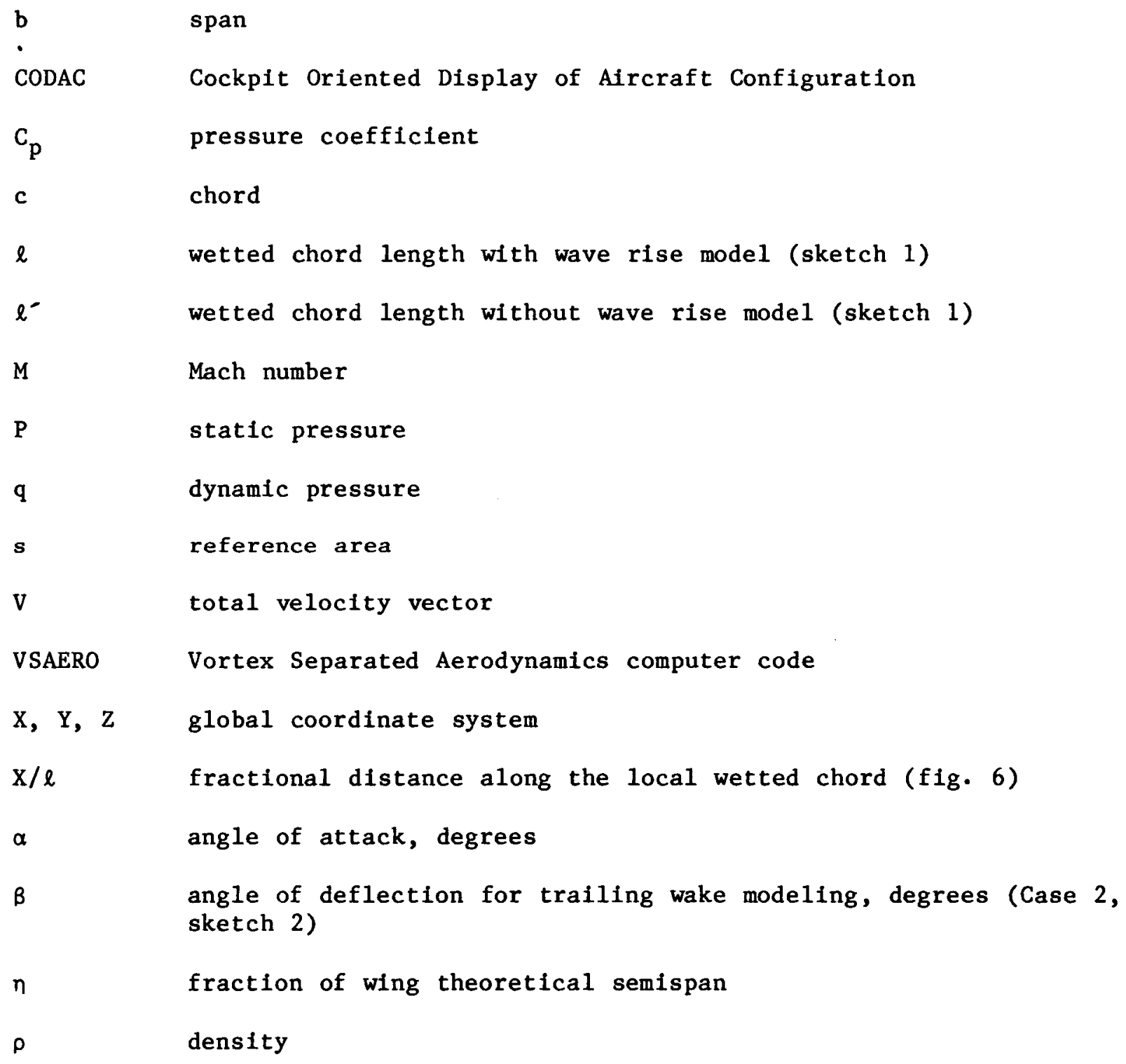




\section{INTRODUCTION}

It is conceivable for an airborne vehicle operating over water to be required to make an emergency water landing due to a system malfunction such as engine power failure. Although aircraft ditching does not frequently occur in reality, a number of experimental studies have been performed (refs. 1-4) with a common objective that is mainly directed at understanding the ditching process and the subsequent hydrodynamic loads. The results from these investigations allow the designers of an aerospace vehicle to make reasonable initial judgments on the design parameters, such as the selection of the material and/or structural arrangements that minimize the impairments resulting from the water loads. It is often possible to incorporate additional features to the design parameters that will give some measure of ditching safety without appreciable penalties to the aerodynamic properties of the aircraft.

Most studies performed in the area of aircraft water ditching have been experimental investigations using dynamically-scaled models or full-scaled vehicles. Although these studies provide qualitative assessments on the effects of the resulting hydrodynamic loads and overall impact on the model, no quantitative information on the problem can be extracted. The purpose of the present study is to determine whether an analytical method can be developed to simulate the aero-hydrodynamic flow field around an aircraft during water ditching. The method is based on linear potential flow theory, employing lower-order panels for aerodynamic surfaces, and a doublet sheet singularities to model the free surface. This doublet sheet, which is sufficiently extended upstream from its intersection with the ditching vehicle, separates the incoming flow into upper and lower part airflow regions. The computed loads, obtained on the configuration surfaces 
interacting with lower part flow region, are subsequently corrected to account for the density differences between air and water. Furthermore, appropriate provisions have been made to model the trailing wake system associated with a ditching configuration.

The primary interest in developing this analytical method for water ditching is its application to the Space Shuttle configuration. As discussed in reference 5, the ascent phase of the Space Shuttle flight profile starts with ignition of the solid rocket boosters and finishes at orbit insertion. In the case of a mission abort in the ascent phase, the orbiter is required to release the solid rocket boosters and the external fuel tank and then return to the launch site. However, if the orbiter is unable to return to the ground airfield facility, an alternative option for the pilot to exercise is to land the vehicle in the ocean. Hence, it is essential to understand the process of ditching as well as its hydrodynamic effects on the vehicle.

No experimental data are available on the ditching of the Space Shuttle orbiter to make any direct hydrodynamic load comparison between the data and the theoretical results on the wetted area. However, efforts have been made to assess the validity of the present analytical ditching method. This validation effort includes a comparison between the theoretical prediction and the experimental hydrodynamic load data acquired on a flat rectangular plate during water ditching.

The theoretical results presented are obtained by employing an aerodynamic panel code called Vortex Separation Aerodynamics (VSAERO) (ref. 6). The code is based on the solution to the Laplace equation about an arbitrary three-dimensional configuration. Source and doublet singularities are distributed in a piecewise constant fashion on each quadrilateral panel. 
The unknown singularity strengths are determined by imposing the external Neumann and internal Dirichlet boundary conditions on each panel.

In addition, a section in the present report addresses the applicability of the VSAERO code to the Space Shuttle configuration in subsonic flow. This section is intended to evaluate the computational results obtained in free air against the available wind tunnel data.

\section{DITCHING METHOD AND EVALUATION}

It is essential to assess the validity of the analytical ditching method developed in the present study. As a result, a literature survey was conducted to retrieve appropriate experimental data on the ditching of a rather geometrically simple configuration. The experimental data are to be used to substantiate the computational results acquired on the same configuration. A literature survey led to the experimental hydrodynamic load data reported by Sottorf (ref. 7). Sottorf's experiments on ditching were conducted in a towing tank on different flat plates at various flow conditions. A set of plots have been selected from his report to provide baseline experimental data for comparative assessments with the computational results obtained from the present analytical ditching method. The data (fig. 1) show the measured chordwise pressure distribution at $8^{\circ}$ angle of attack and 19.685 ft/s. (1.e., $6 \mathrm{~m} / \mathrm{s}_{.}$) towing speed for a simple rectangular plate at various span locations. This set of experimental data appeared to be sufficient for the evaluation purposes of the present analysis. 


\section{Test Case Configuration}

A rectangular plate is generated to provide a computational test case configuration. The plate is constructed from a circular-arc section (thickness ratio of $1.7 \%$ with maximum occurring at mid-chord), having a flat lower surface and aspect ratio of 2.33 . The three-view computer drawing of the constructed surface panels is shown in figure 2. The configuration is pitched-up about the trailing edge and set at $8^{\circ}$ angle of attack which corresponds to the experimental hydrodynamic data. The complete configuration is represented using 391 surface panels.

\section{Free Surface Modeling}

The free surface of the water is represented by doublet sheet singularities with an imposed no-flow through boundary condition. This flat surface, situated at zero angle of attack with respect to the freestream, begins at its intersection with the lower surface of the ditching configuration and extended upstream to about three times the configuration root chord (sketch 1). The free surface can be envisioned as a dividing stream surface which separates the incoming flow into two parts; the upper surface air region and the lower surface water region. Although theoretically, both regions are exposed to air flow, the aerodynamic loads computed for the lower surface wetted region are then corrected to account for the water density.

It should be noted that the doublet sheet used to model the free surface does not allow for surface distortion. However, a study is performed to investigate the effect of wave rise (Sketch 1) on the surface load distribution. As discussed in reference 8 , the wave rise occurs in front of a 


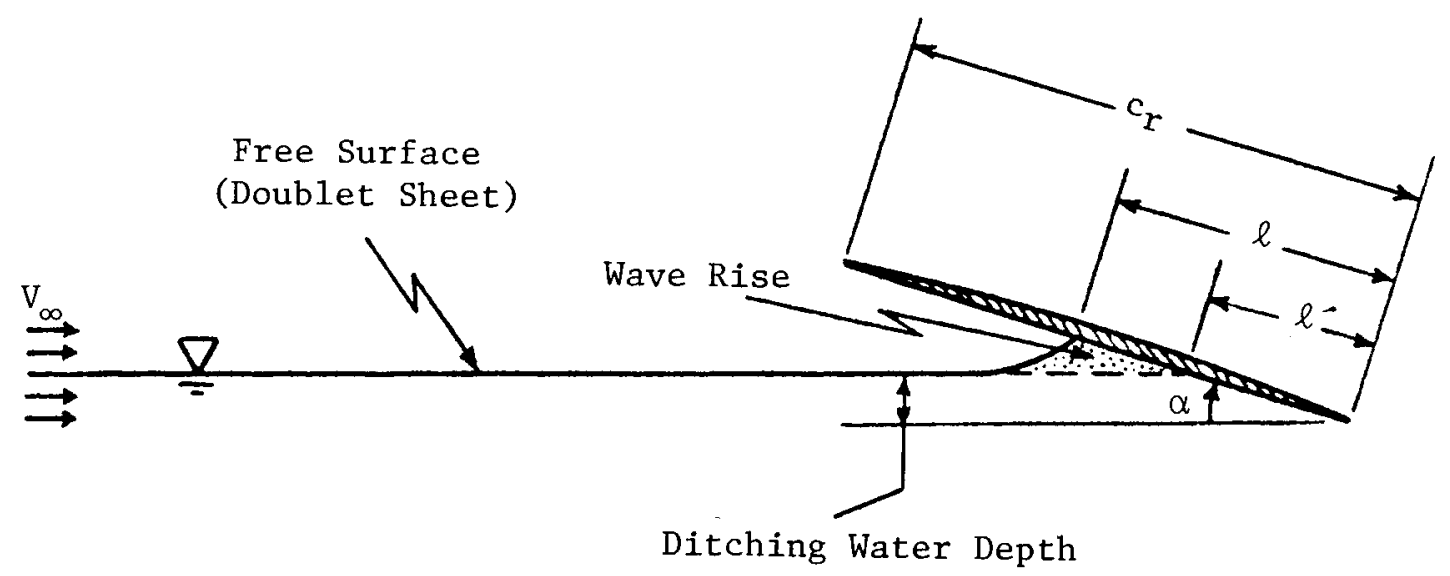

Sketch 1. Cross section of a flat bottom rectangular plate during water ditching.

flat-bottom plate during planing. This wave rise causes the running wetted length ( $\ell$ ) to be larger than the length $\left(\ell^{-}\right)$defined by the undisturbed water level intersection with bottom surface of the plate. As expected, this study revealed that the volume of the wave rise region can be altered by changing the ratio of $\ell / \ell^{-}$. Furthermore, any increase in the wave rise volume causes a flow deceleration in the region. This flow retardation results in an increase in the positive pressure peak in the vicinity of the wave rise cavity region. It is difficult to justify any specific value for the $\ell / \ell^{-}$ratio, because it depends on many variables such as the configuration geometry, angle of attack, depth of water (measured vertically from the configuration trailing edge to the free surface), ditching speed, etc. However, this ratio is given in Sottorf's report for the flat rectangular plate that was tested in a towing tank. As a result, this ratio was appropriately used to determine the length $\ell$ for a given length $\ell^{-}$which 
is known when a water ditching depth is selected. Furthermore, a smooth curve was used to define the shape of the free surface curvature just before intersecting the lower surface of the ditching configuration. A similar procedure was used to model the wave rise region for Shuttle configuration during ditching.

\section{Trafling Wake Hodeling}

Three different approaches were studied in trying to model the trailing wake system of the test configuration during water ditching. A streamwise cut through the ditching configuration, as we11 as the modeled free surface and the various wake models studied, are shown in sketch 2 . As seen from the sketch, the first approach does not allow a change to occur in the vertical height level of the wake as it leaves the configuration trailing edge. The second approach allows the tralling wake system to vary linearly starting at the configuration trailing edge and terminating downstream at the free-surface atmospheric level where it becomes constant. The angle at which the wake lines leave the trailing edge is chosen to be twice the configuration angle of attack (i.e., $\beta=16^{\circ}$, see sketch 2 ). The third approach is basically similar to the second approach with the exception that the trailing wake system is defined by a curved path rather than a linear connection. This curved wake system leaves the trailing edge tangent to the configuration lower surface and blend smoothly into the free surface atmospheric level downstream.

The computed results on the test case configuration utilizing the wake system defined in approach 3 will be shown later in this section. However, it is important to note that the effects of different aforementioned trailing wake modeling on the computed aerodynamic load distributions appeared 

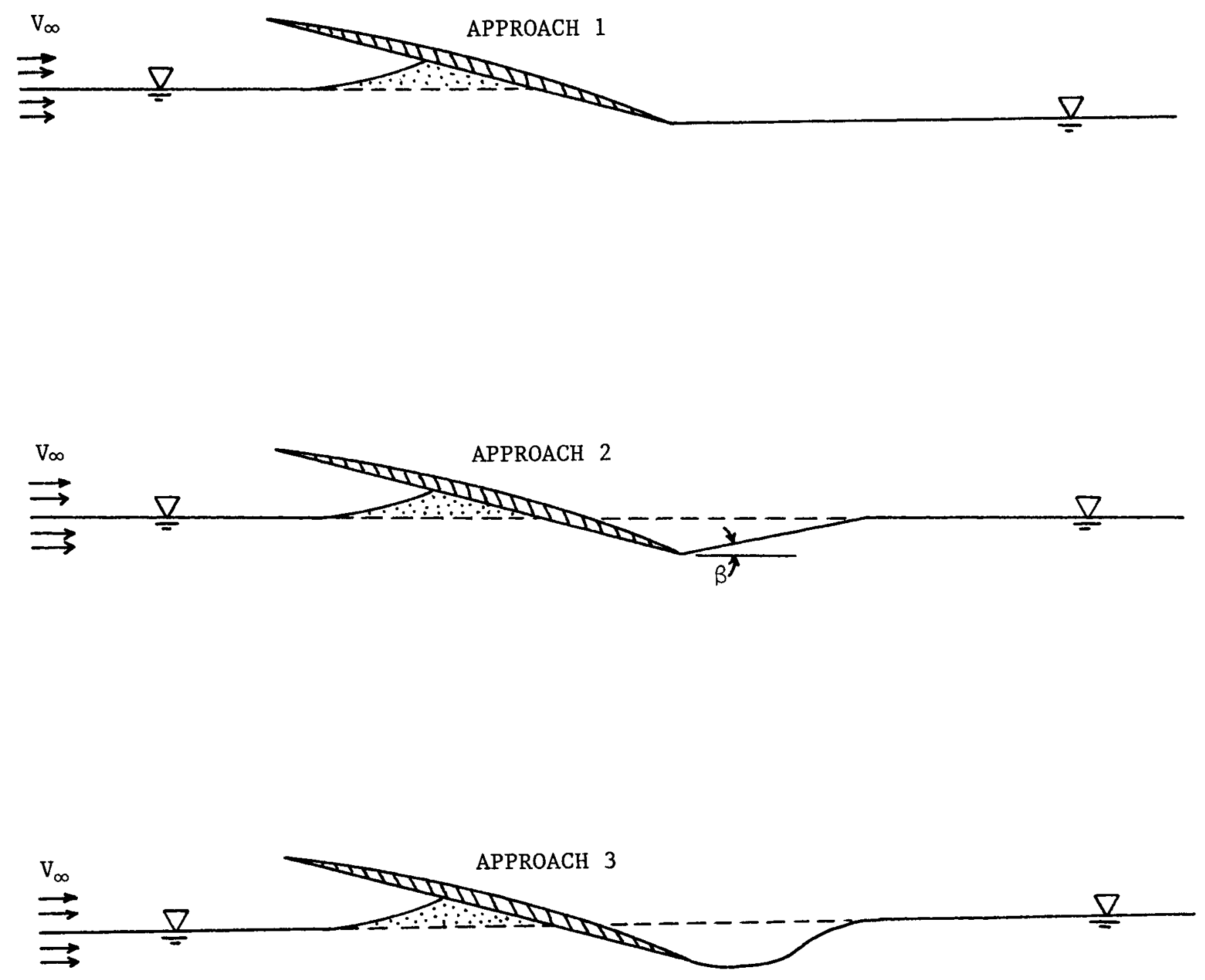

Sketch 2. Trailing wake models studies for the ditching of a flat bottom rectangular plate. 
to be sma11. Hence, a judgmental decision had to be made as to which wake modeling should be chosen to be employed for the ditching application to the Shuttle configuration. For the purpose of simplicity, it was decided to select the trailing wake system defined in the first approach. This selection does not require any modification to the wake system other than what the VSAERO code would automatically generate.

\section{Density Correction}

The pressure coefficient is defined as:

$$
C_{p}=\frac{P-P_{\infty}}{1 / 2 \rho V_{\infty}^{2}}=\frac{P-P_{\infty}}{q}
$$

where $\rho, V_{\infty}$, and $q$ are the fluid density, freestream velocity, and dynamic pressure, respectively. According to linear potential flow theory, the fluid density is assumed to be constant (i.e., incompressible flow). As a result, the term $\rho$ in the above equation can be interpreted as a scaling factor which remains constant for a given fluid media. For example, the constant density assumption allows the aerodynamic pressure coefficients computed on a configuration to be converted to hydrodynamic loads by a simple multiplication factor determined by the ratio of air-to-water density. Hence, equation (1) becomes :

$$
\text { for air } \quad C_{p}=\frac{P-P_{\infty}}{1 / 2 \rho_{a} V_{\infty}^{2}}=\frac{P-P_{\infty}}{q_{a}}
$$

and

$$
\text { for water } C_{p}=\frac{P-P_{\infty}}{1 / 2 \rho_{a} V_{\infty}^{2}} \cdot \frac{\rho_{a}}{\rho_{w}}=\frac{P-P_{\infty}}{q_{w}}
$$


where the subscripts a and $w$ denote the air and water properties, respectively.

The experimental hydrodynamic load distribution for the test case configuration have been reported (ref. 7) in the form of a pressure difference between the local and atmospheric level (i.e., $P-P_{\infty}$ ). To be consistent, attempts have been made to convert the computed loads to that of the experimental form. It follows from equations (2) and (3) that;

$$
\begin{aligned}
& P-P_{\infty}=C_{p} q_{a} \\
& P-P_{\infty}=C_{p} q_{w}
\end{aligned}
$$

Furthermore, the selected experimental data on the test case configuration were obtained for $8^{\circ}$ angle of attack and freestrem velocity of $19.685 \mathrm{ft} / \mathrm{s}$. As a result, the corresponding air and water dynamic pressures are given by:

$$
\begin{aligned}
& q_{a}=1 / 2 \rho_{a} v_{\infty}^{2}=1 / 2 \quad\left(.00237 \frac{\mathrm{slug}}{\mathrm{ft}^{3}}\right)\left(19.685 \frac{\mathrm{ft}}{\mathrm{s}}\right)^{2} \frac{\mathrm{ft}^{2}}{144 \mathrm{in}^{2}} \\
& q_{a}=0.00319 \text { Psi } \equiv 2.24 \mathrm{~mm} \text { of water } \\
& q_{w}=1 / 2 \rho_{\mathrm{w}} v_{\infty}^{2}=1 / 2\left(1.94 \frac{\mathrm{slug}}{\mathrm{ft}^{3}}\right)\left(19.685 \frac{\mathrm{ft}}{\mathrm{s}}\right)^{2} \frac{\mathrm{ft}^{2}}{144 \mathrm{in}^{2}} \\
& q_{w}=2.61 \text { Psi } \equiv 1836.77 \mathrm{~mm} \text { of water. }
\end{aligned}
$$

* The hydrodynamic pressure loads in reference 7 are given in $\mathrm{mm}$ of water. The following relation is used to convert Psi unit to $\mathrm{mm}$ of water.

1 Psi $=703.68 \mathrm{~mm}$ of water 
The above known values of the dynamic pressures for air and water are coupled with the computed aerodynamic pressure coefficients in equations (4) and (5) to determine the surface local-atmospheric pressure difference on the ditching configuration.

\section{Results and Discussions}

The VSAERO computer code is applied to the test case configuration to evaluate the validity of the present analytical ditching method. An isometric veiw of the surface panels representing the ditching configuration set at 8 angle of attack as well as the adopted trailing wake system and the free surface modeling is shown in figure 3. The surface velocity field solutions computed at the center point of each panel on the test case configuration are shown in figure 4. This figure also shows those velocity vectors computed on the free surface just ahead of the ditching configuration which have been affected the most. These solutions clearly show the flow retardation in the cavity region between the waterline and the lower surface of the leading-edge portion of the ditching configuration. Although the velocity magnitudes are small in the cavity region, it appears that the magnitude of the sidewash velocity component increases as the flow approaches the outboard tip region where the open end allows for a rapid discharge of the trapped cavity flow into the main stream.

The chordwise pressure coefficients computed on the test case configuration along with the corresponding geometry sectional cut are plotted in figure 5. In addition, the figure shows the pressure coefficients on the free surface panels that are situated just ahead of the ditching configuration. It should be noted that the pressure coefficients and the total 
velocity magnitudes, computed on the free surface panels upstream of those shown in the figure, approach those of the freestream flow conditions. Furthermore, these solutions are all computed for free air and have not been corrected to account for the water density. It is evident from figure 5 that there is no sign of a drastic change in the pressure distributions computed on the upper surface of the ditching configuration. However, as expected, it appears that the ditching process has significant effects on the configuration lower surface pressure distribution. The configuration lower surface experiences two distinct flow characteristics which are separated by the presence of the free surface. The flow passing above the free surface is trapped in the cavity region and the flow passing under the free surface proceeds towards the configuration trailing edge. It can be seen from figures 4 and 5 that the reduced velocity magnitude (approximately zero) in the cavity region results in a compressed flow which drives the computed pressure coefficients towards unity. However, the flow passing under the free surface is mildly expanded on the lower surface of the ditching configuration which reduces the pressure coefficients to about zero at the trailing edge. The lower surface panels that are aft of the free surface intersection with the configuration are considered to be exposed to water. Consequently, the pressure coefficients computed on the wetted panels are corrected to account for the change in the density.

The hydrodynamic pressure distribution on the wetted panels have been obtained from the computed pressure coefficients using equation (5) and are plotted in figure 6. For comparison purposes, this figure also shows the experimental data for a flat rectangular plate given by reference 7 . It should be noted that the theoretical solution computed at inboard $(n=0.07)$ 
and the outboard $(n=0.93)$ span stations are slightly different from those of the experimental locations, because the theoretical solutions are computed at the center point of each surface panel rather than at the edges. The figure shows that the overall comparison between computational results and the experimental data are generally good. To be more explicit, one can confine the existing disagreements to three main regions. These are the trailing edge, the t1p, and the wave rise region where the maximum positive pressure occurs. It appears that the theoretical results can be manipulated to compel an even better comparison with the data, by simply modifying the trailing wake system, wave rise region, and/or extending/shaping of the free surface outboard of the tip region. However, since the water surface characteristics for the test case configuration are not known in these regions, no attempts were made to further modify the original free surface modeling.

\section{SPACE SHUTTLE ANALYSIS}

The preliminary application of the VSAERO computer code to the Space Shuttle water ditching is discussed in three parts. The first part is a discussion on the Space-Shuttle geometry preparation. The second part addresses the validity of the computed results on the Shuttle configuration In free air. This validation effort is established through a comparison between the computed pressure coefficients and the avallable experimental wind tunnel data. The third part of the study includes an investigation on the computational results that are obtained on the Shuttle configuration for three different altitudes with respect to the free surface. The three different altitudes are designed to simulate the flow around the orbiter in: (a) free air; (b) vicinity of water surface; and (c) water ditching. 


\section{Geonetry Preparation}

The geometry preparation often plays an important part of any computational analysis especially when a lower order (constant source and doublet singularity distributions) surface panel aerodynamic codes such as VSAERO is being utilized. For such computer codes, fine surface panel resolution on the aircraft configuration is required for an accurate computational results. However, the availability of the 1000-panel version of the VSAERO code limited the maximum number of surface panels that could be used in the present study. As a result, preventive action is taken early on to ensure that the limitation on the allowable number of surface panels and/or the accuracy of the surface panel resolution does not create any future complication. This action required a single geometry to be generated for the Space Shuttle that could be used in proceeding analysis without any geometrical changes. The analysis includes both the free air evaluation of the VSAERO results against the experimental data and the shuttle ditching application with free surface modeling. It should be noted that a11 the geometry manipulations such as surface paneling rearrangement, determination of the free surface intersection with the Shuttle configuration, etc. are performed interactively using a computer code called GEOMX (ref. 9). Moreover, all the dimensions reported on the Shuttle configuration are taken from a full-scale vehicle.

An angle of attack of $12 \mathrm{deg}$. and zero Mach number are chosen as the flow conditions used for the Shuttle ditching analysis. Furthermore, the waterditching depth (height measured vertically from the Shuttle configuration minimum point to the free surface) of 98.3 inches is selected to provide the height level of the free surface relative to the configuration. As the first 
step, the intersection of the free surface with the configuration is required for any future paneling rearrangements. The Shuttle configuration with its original surface panels is initially pitched up to the desired $12 \mathrm{deg}$. angle of attack. A horizontal cut through the complete configuration is made at the given height level selected for the free surface. Figure 7 shows the side and the front view of the Shuttle configuration with a conventional paneling arrangement. This figure also shows the location of the cut as well as the resulting intersection contour. A more informative view of the free surface Intersection with the windward side of the Shuttle configuration is shown in figure $8(a)$. The panels on the lower surface of the wing as well as the cargo bay are modified around the free surface intersection line. As shown in figure $8(b)$, this modification on the windward side of the configuration is necessary to separate the wetted panels exposed to the water from those exposed to the air flow. Moreover, this new arrangement provides an imporved panel resolution and also allows for an exact abutment between the surface panel edges of the free surface and the Shuttle lower surface. The total number of panels on the modified Shuttle geometry is 841 , excluding the vertical tail. The vertical tail has been neglected because it appears that its presence has a minimal aerodynamics effect on the present analysis.

Now that the free surface intersection line with the windward side of the Shuttle configuration has been determined, the construction of the free surface model only depends on a dimension which defines its upstream extent. Consequent1y, it appeared sufficient to extend the free surface model to about 1000 inches (slightly larger than the wing root chord) upstream. Furthermore, a small geometrical modification is made to the flat free surface to model the wave rise curvature just before its intersection with the configuration. This 
modification caused the actual free surface model to be lowered to 88.3 inches (i.e., 10 inches lower than the original leve1) upstream of the wave rise region. The three-view computer drawings of the final free surface model constructed from 156 panels is shown in figure 9. Also, an exploded isometric view of the complete surface panels on different components of the Shuttle configuration as well as the modeled free surface is shown in figure 10 . It is important to note that the span extend of the free surface outboard of its intersection with the wing leading edge is not modeled in the present study. This decision is made because of the difficulty in predicting an appropriate shape for the free surface model above the submerged wing tip region. This region, located under the free surface cutting plane is clearly shown in the front view of the Shuttle configuration in flgure 7 . The absence of the free surface in the tip region would allow the spanwise flow that is growing above and below the modeled free surface inboard of the submerged tip region, to split at the wing leading edge with no geometrical constraints.

\section{Free Air Evaluation}

This part of the study evaluates the applicability of the VSAERO code to the Space Shuttle configuration in free air. This evaluation is verified through a direct comparison between the computed pressure coefficients and the available experimental wind tunnel data at $12.5^{\circ}$ angle of attack and 0.6 Mach number. The experimental data (ref. 10) are obtained on a 0.03-scale model tested in the NASA/ARC Unitary plan wind tunnels. The VSAERO surface panel representation of the Shuttle configuration is shown in figure 11, from two perspectives. These figures are generated interactively using the Cockpit Oriented Display of Aircraft Configuration (CODAC) computer code.*

*This code was developed by Bradford Bingel and Dana Hammond of Computer Science Corporation, Applied Technology Division, Hampton, VA, and has not yet been formally documented. 
The VSAERO computed surface velocity field solution obtained on the Shuttle configuration is shown in figure 12. Presented are the resultant velocity vectors computed at the center of each pane1. Furthermore, the computed chordwise pressure distributions on the wing panel at four different semispan locations are shown in figure 13. In addition, this figure also shows the wind tunnel experimental data as well as the wing cross-sectional geometry for the same semispan location. The horizontal and vertical axis represent the full-scale coordinates of the Shuttle configuration. The computed pressures compare very well with the available data except on the forward part of the upper surface for the last semispan station (i.e., $n=.89)$. It is interesting to note that the crossing of the experimental upper and lower surface pressure distribution near the wing trailing edge is well predicted by the theory across the span.

\section{Ditching Application}

As part of the analytical ditching application to the space Shuttle configuration, it is instructive to include the corresponding free air and ground effect calculations. A total of three cases are examined, at $12^{\circ}$ angle of attack and Mach number of zero, with various altitudes with respect to the ground (i.e., water surface). These altitudes are designed to simulate the flow conditions around the Shuttle configuration in: a) free air; b) vicinity of water surface; and c) water ditching. A side-view panel representations of the orbiter operating at these altitudes are shown in figure 14. This figure also shows the truncated trailing wake models associated with each case. Furthermore, two isometric views of the Shuttle configuration with the modeled free surface are shown in figure 15 . The 
geometry on the top clearly illustrates the outboard extend of the free surface with respect to the wing span and its position along the leading edge. Moreover, the geometry shown on the bottom part of the figure illustrates the surface panel arrangements on the free surface and the wetted region on the Shuttle configuration.

The surface velocity field solutions computed by the VSAERO code on the Shuttle configuration are shown in figure 16 for the three cases studied. It is difficult to differentiate any velocity field variation between the inground and ditching solutions except around the wing leading edge where the upwash velocity component has noticibly increased. In addition, it is interesting to note the growth of the spanwise flow on the free surface near the configuration during water ditching.

The computed pressure coefficients on the Shuttle configuration are shown in figure 17, for various cases studied. The figure also shows the corresponding streamwise sectional-cut through the modeled configuration. it should be noted that the VSAERO code has a built-in feature for ground effect analysis which allows a user to specify the $x-y$ plane at zero elevation (i.e., $z=0)$ to represent the ground. Hence, the surface pane1 coordinates associated with a configuration are required to be transferred up above the $x-y$ plane according to the desired ground height elevation. As a result, the $z$-coordinates associated with the streamwise sectional cut shown for ground effect in figure 17 are different from those of the free air and/or the ditching. Furthermore, the pressure coefficients that are shown in the figure are all computed for air. No attempts are made here to correct the load distributions on the configuration wetted region to account for the difference in density of the fluid media. However, as discussed earlier, the only 
parameter needed for the conversion of the computed aerodynamic properties to those of hydrodynamic is the dynamic pressure. The dynamic pressure is readily determined from landing speed of the ditching configuration. For example, two steps are required to compute the hydrodynamic pressure distribution on the wetted panels of the Shuttle configuration having a ditching speed of 100 knots (i.e., $168.78 \mathrm{ft.} / \mathrm{s}$ ). The first step is to find $\mathrm{q}_{\mathrm{w}}$ as follows

$$
\begin{aligned}
q_{w}=\frac{1}{2} \rho_{w} v_{\infty}^{2} & =\frac{1}{2}\left(1.94 \frac{\mathrm{slug}}{\mathrm{ft}^{3}}\right)\left(168.78 \frac{\mathrm{ft}}{\mathrm{s}}\right)^{2} \frac{\mathrm{ft}^{2}}{144 \mathrm{in}^{2}} \\
q_{w} & =191.9 \mathrm{Psi}
\end{aligned}
$$

The second step is to multiply the above value by all the computed aerodynamic pressure coefficients.

The general conclusions deduced from figure 17 are summarized in the following steps.

1) It is evident from the distribution of the computed pressure coefficlents that the presence of the ground results in the upper-surface flow expansion especially in the outboard region, and the lower-surface flow compression particularly in the inboard region, as expected.

2) It appears that the ditching operation has minimal effects on the configuration upper-surface pressure distributions with the exception of the flow expansion around the leading-edge portion of the wing section where the outboard tip of the free surface is located. This expansion is largely due to the growth of the spanwise flow in the cavity region between the free surface and the lower surface of the Shuttle configuration. 
3) The pressure distribution on the fuselage of the Shuttle configuration during ditching (bottom of fig. 19(a)) reveals two clear stagnation points (i.e., $\mathrm{V} \approx 0, \mathrm{C}_{\mathrm{p}} \approx 1.0$ ) at a span station positioned approximately along the configuration plane of symmetry. The first one is located on the lower surface of the forebody and the second one is at the free surface intersection with the configuration lower surface. There is no evidence of these stagnation points occurring outboard of this station, because the magnitude of the sidewash velocity component keeps growing in the spanwise flow direction.

4) The presence of the free surface causes the lower surface of the Shuttle configuration to experience two distinct flow characteristics. The upper free surface flow which is trapped in the cavity region and the lower free surface flow which proceeds towards the configuration trailing edge. The compressed air flow in the cavity region results in an approximately the same pressure distribution on the configuration lower surface as well as on the free surface. Upstream of the cavity region, the pressures on the free surface approach those of the freestream conditions. The lower freesurface flow starts to expand once passed downstream of the waterline intersection with the Shuttle lower surface, thereby, reducing the neighboring surface pressure coefficients.

\section{CONCLUDING REMARKS}

The present study demonstrated the applicability of a simple method developed for aero-hydrodynamic load analysis of an airborne vehicle during water ditching. The method employs an aerodynamic panel code, based on linear potential flow theory, to simulate the flow of air and water around the 
ditching configuration. A doublet sheet is used to represent the water free surface. Although all the theoretical load distributions are computed for air, provisions are made to correct the pressure coefficients computed on the configuration wetted region to account for the water density.

The validity of the developed method is first examined against a rectangular plate configuration with available experimental hydrodynamic load data. A reasonable comparison between the computational results and experimental data are revealed for the wetted region. The success of this validation effort led to the application of the method to analyze the ditching effects on the Space Shuttle configuration. The computed aerodynamic pressure coefficients on the shuttle configuration with modeled free surface are reported in the general form. These coefficients can be corrected subsequently to account for the water density on the wetted areas for any desired Shuttle ditching (landing) speed.

\section{Acknowledgment}

Research was provided by the National Aeronautics and Space Administration under NASA Contract No. NAS1-17919 while the author was in residence at Vigyan Research Associates, Inc., 30 Research Drive, Hampton, Virginia 23666-1325. 


\section{REFERENCES}

[1] Thomas, W. L.: Ditching Investigation of a 1/20-Scale Model of the Space Shuttle Orbiter. NASA CR-2593, October 1975.

[2] Fisher, L. J. and Hoffman, E. L.: Ditching Investigations of Dynamic Models and Effects of Design Parameters on Ditching Characteristics. NACA Report 1347, 1958.

[3] McBride, E. E.: Preliminary Investigation of the Effects of External Wing Fuel Tanks on Ditching Behavior of a Sweptback Wing Airplane. NACA TN $3710,1956$.

[4] McBride, E. E. and Fisher, L. J.: Experimental Investigation of the Effect of Rear-Fuselage Shape on Ditching Behavior. NACA TN 2929, 1953.

[5] McSwain, G.: Shuttle Ascent GN\&C Postflight Results. Shuttle Performance: Lessons Learned. NASA CP-2283, Part 1, March 1983, pp. 581-594.

[6] Maskew, B.: A Computer Program for Calculating the Nonlinear Aerodynamic Characteristics for Arbitrary Configurations. NASA CR-166476, December 1982.

[7] Sottorf, W.: Experiments with Planing Surfaces. NACA TM 6611, March 1932. 
[8] Savitsky, D.: Hydrodynamic Design of Planing Hulls. Marine Technology, Vo1. 1, No. 1, October 1964, pp. 71-95.

[9] Hall, J. F.; Neuhart, D. H.; and Walkley, K. B.: An Interactive Program for Manipulation and Display of Panel Method Geometry. NASA CR-166098, March 1983.

[10] Chee, E.; and Marroquin, J.: Results of Test Using a 0.030-Scale Pressure Loads Space Shuttle Orbiter Model $(47-0)$ in the NASA/ARC Unitary Plan Wind Tunnels (OA149A). NASA CR-151780, Vol. 2 of 3 , December 1979 . 


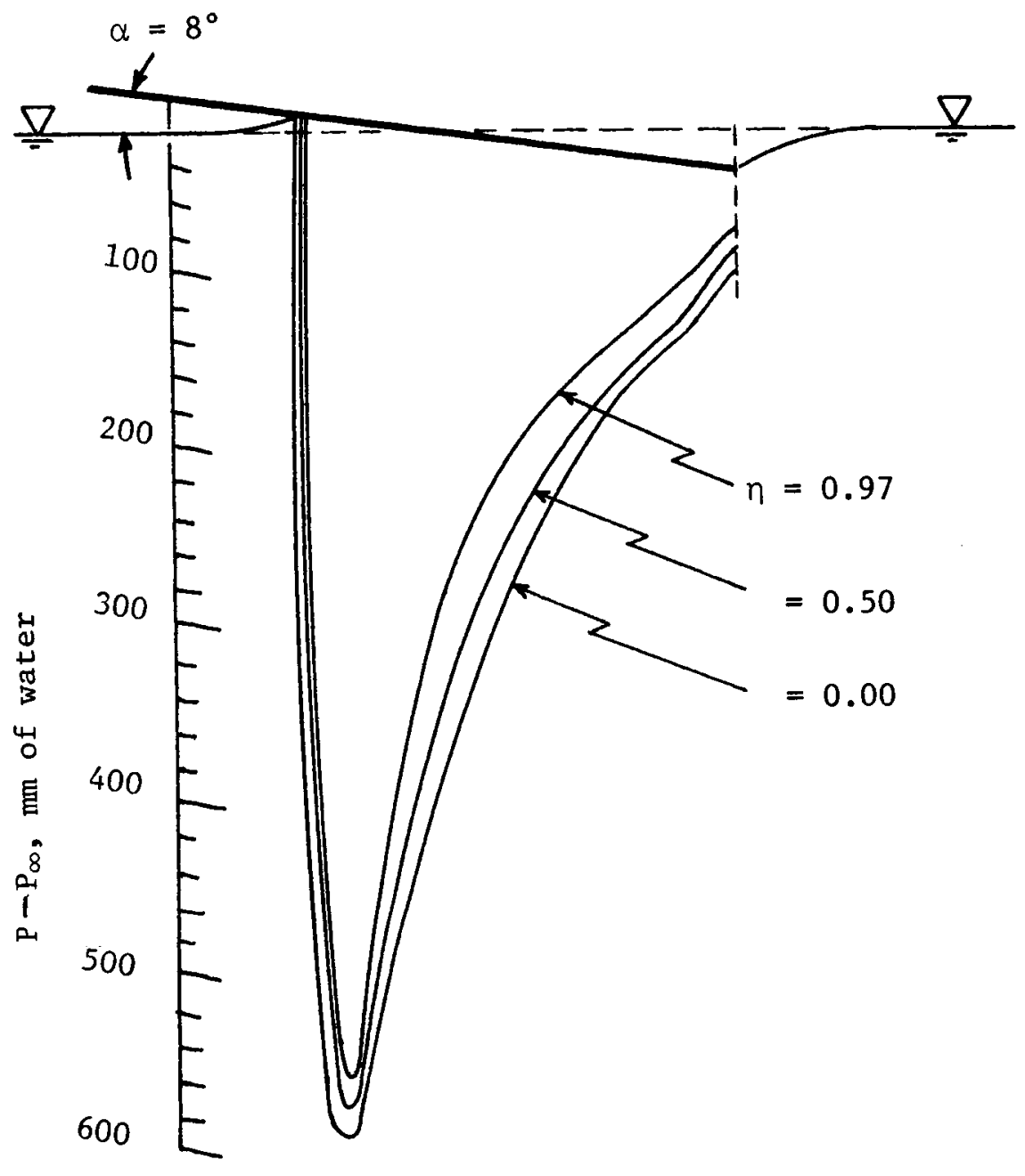

Figure 1. Experimental pressure distribution on a flat rectangular plate at $\alpha=8^{\circ}$ and $V=19.685 \mathrm{ft} / \mathrm{s}$. 
ORIGINAL PAGE IS

OF POOR QUALITY
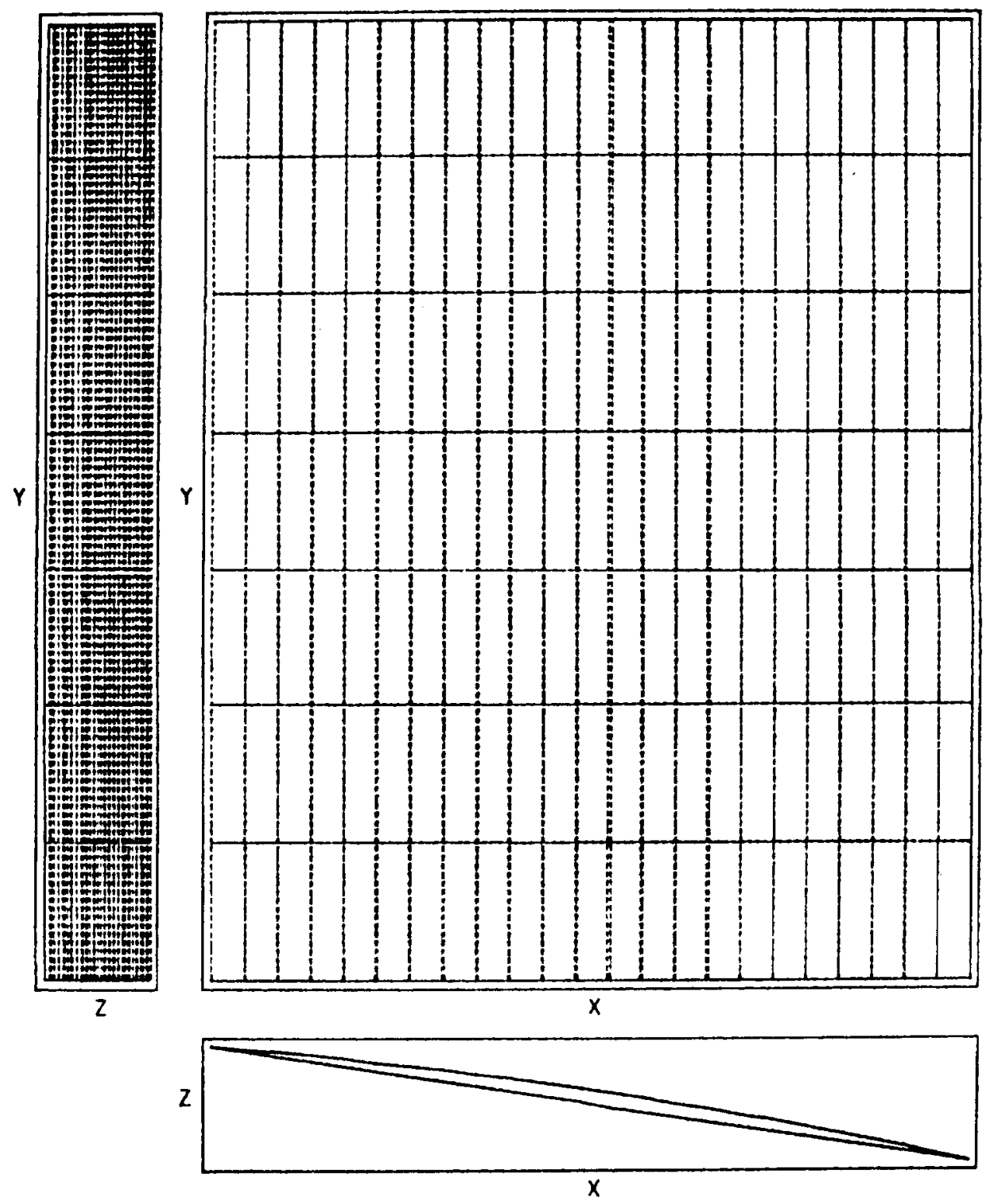

Figure 2. Surface panel representation of the test case configuration at $8^{\circ}$ angle of attack. 

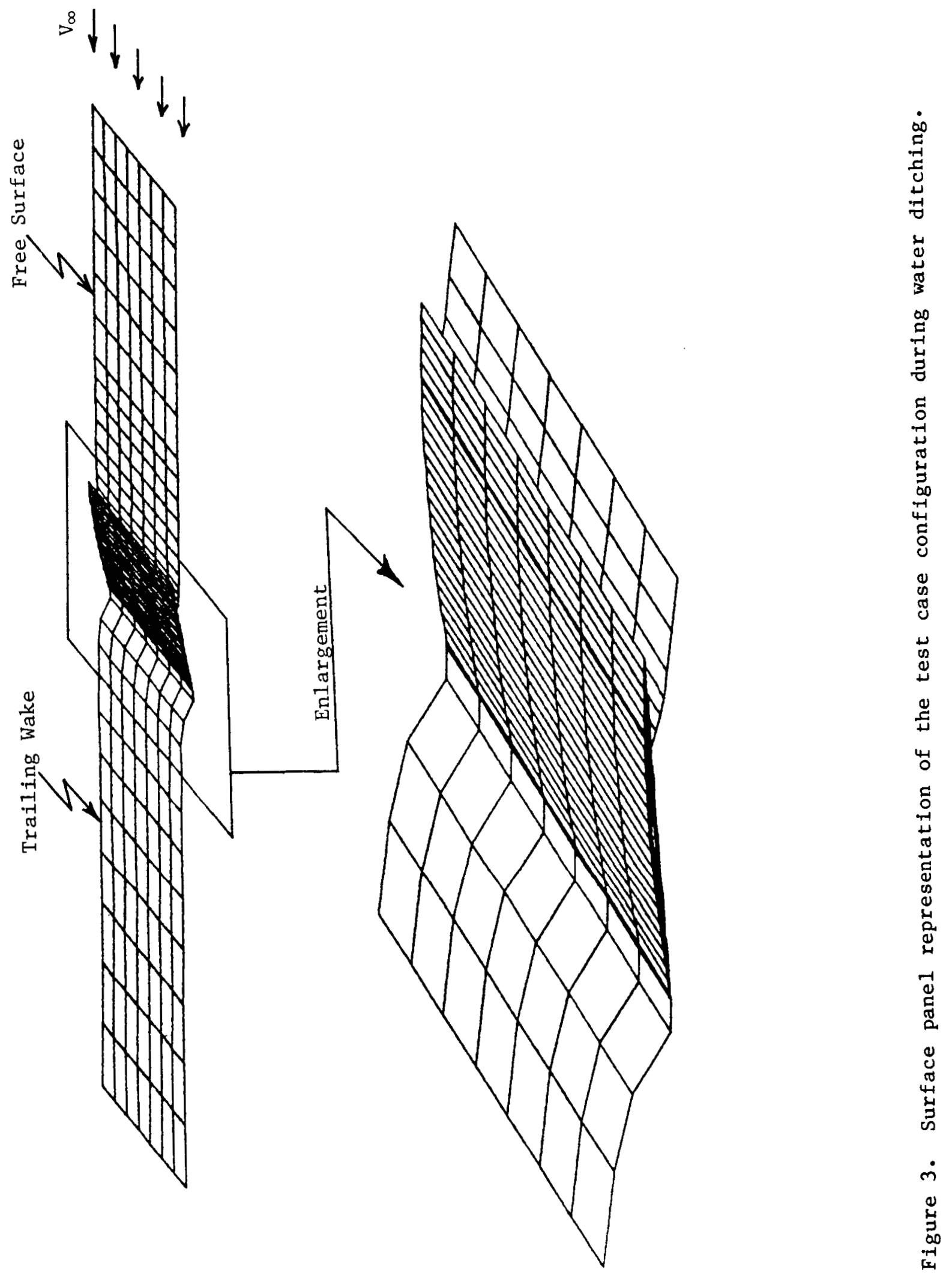


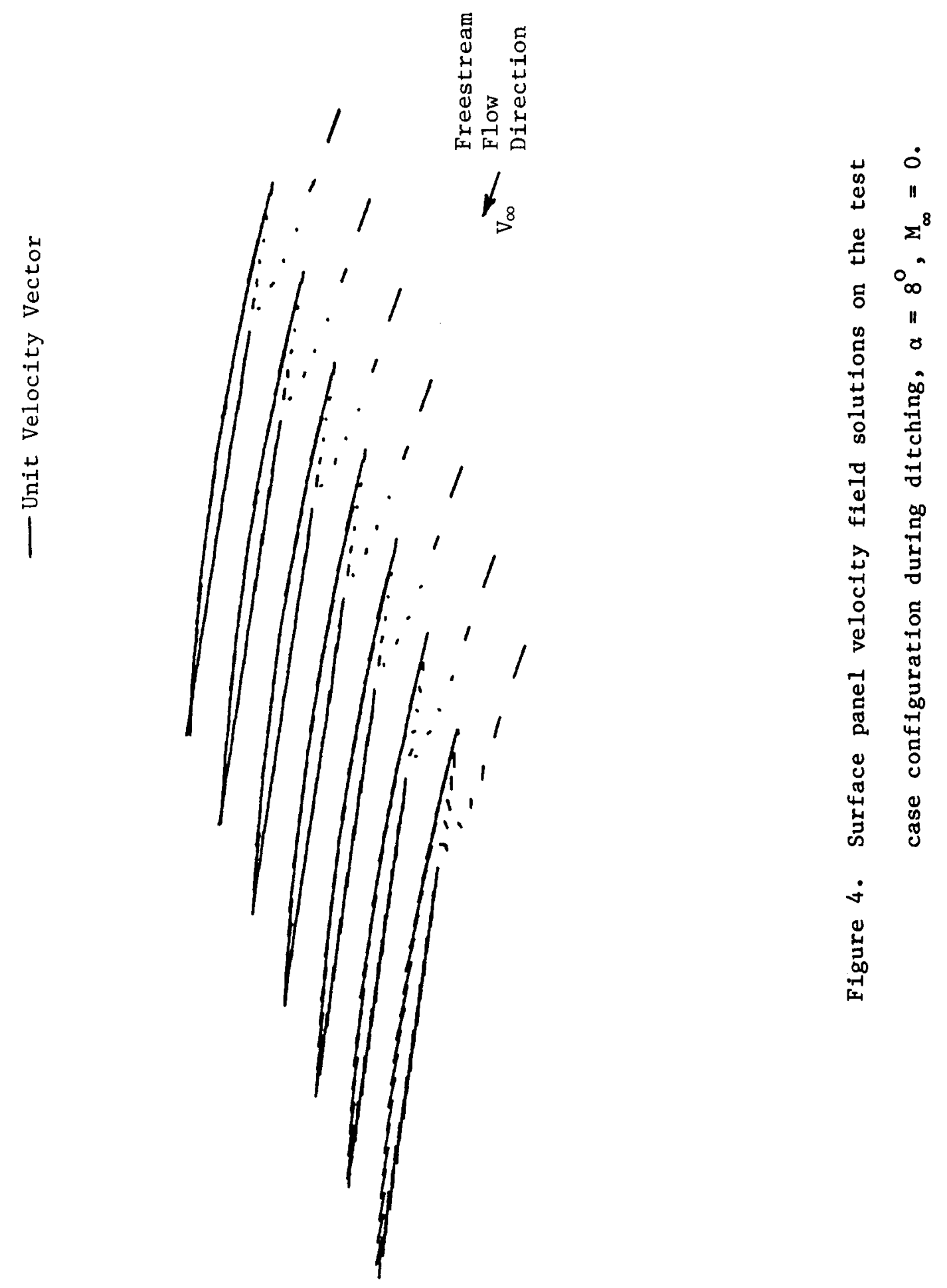




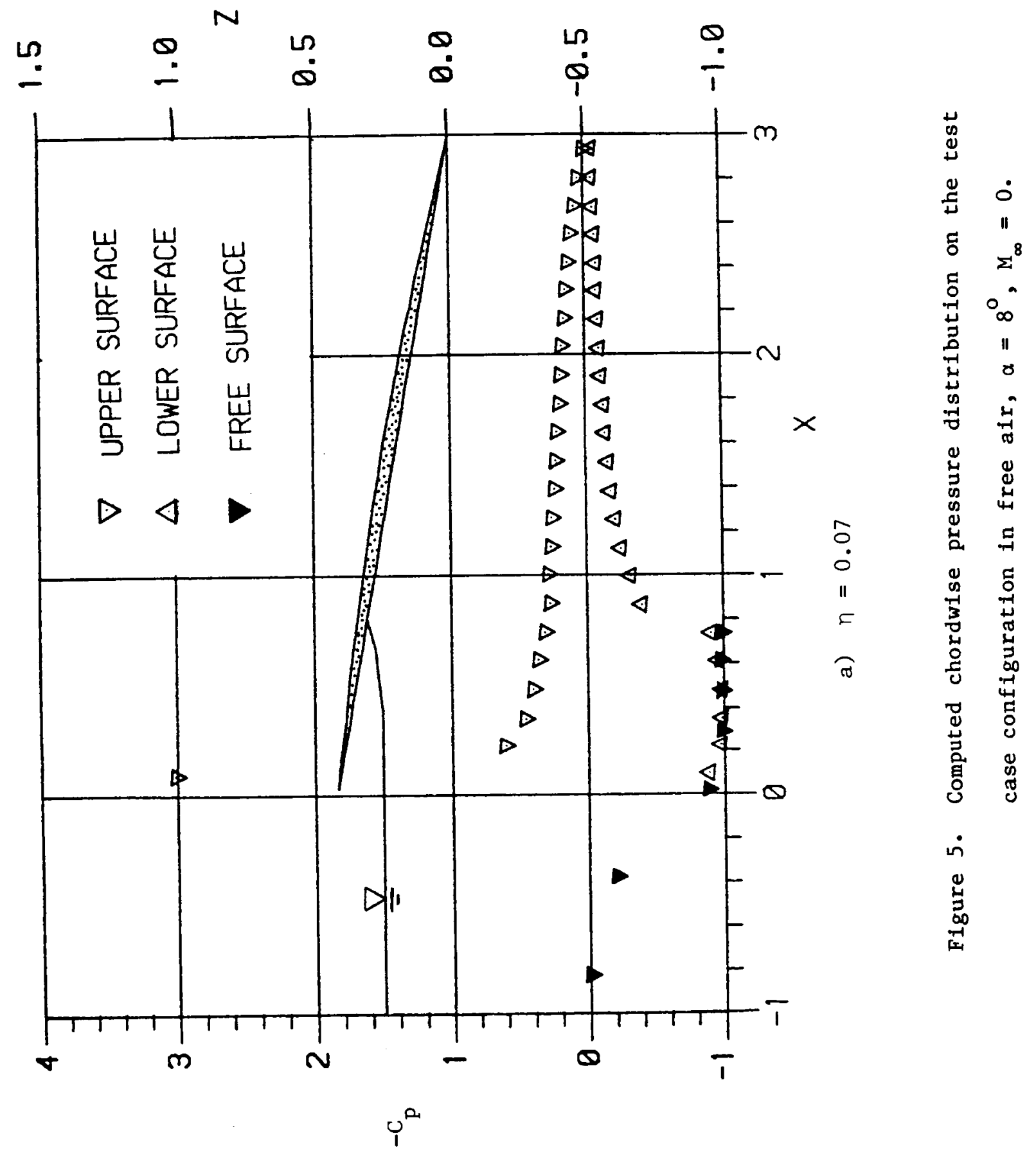




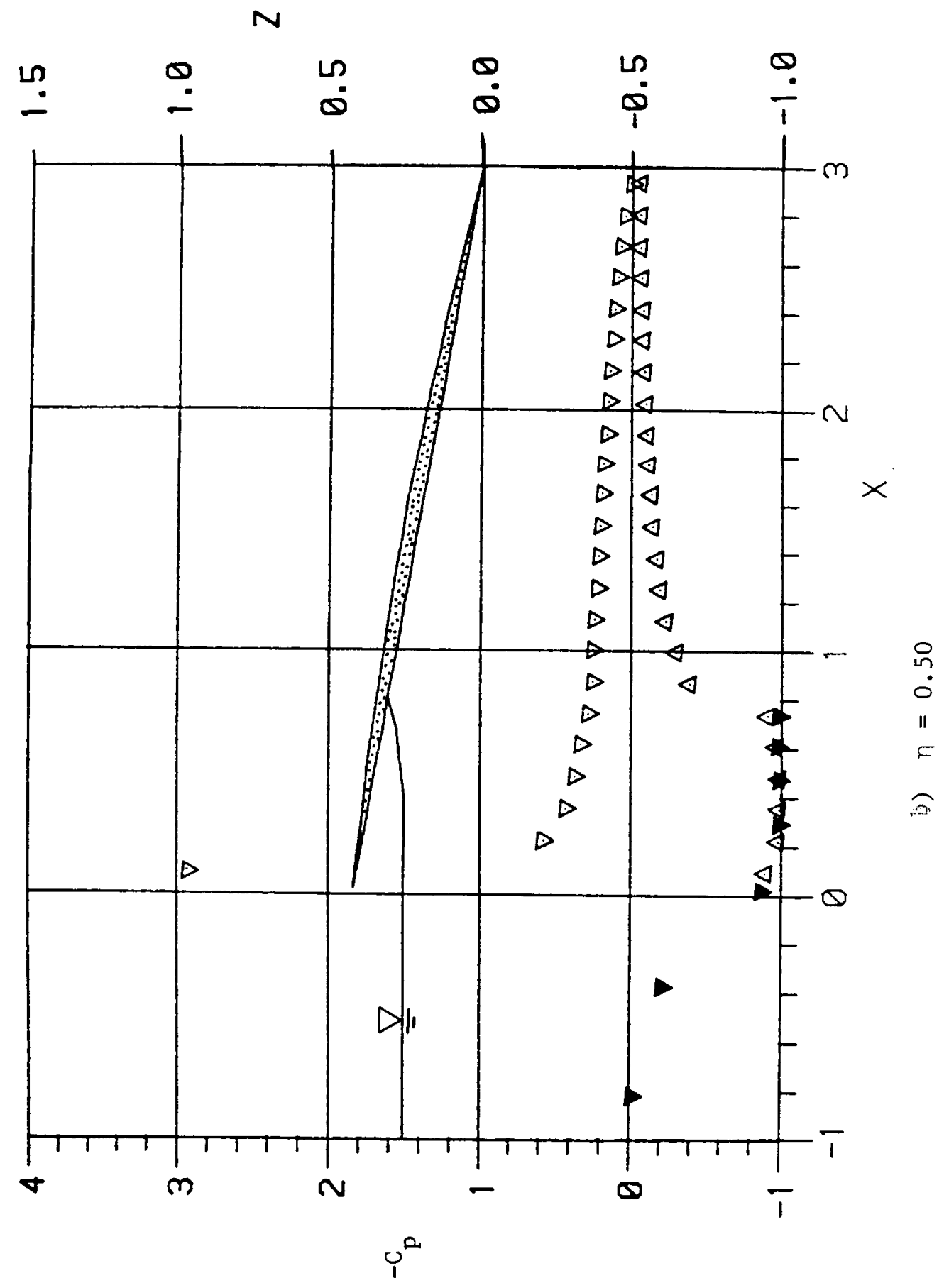

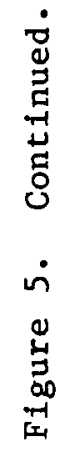




$$
\text { MII }
$$


ORIGINAL PAGE IS

OF POOR QUALITY

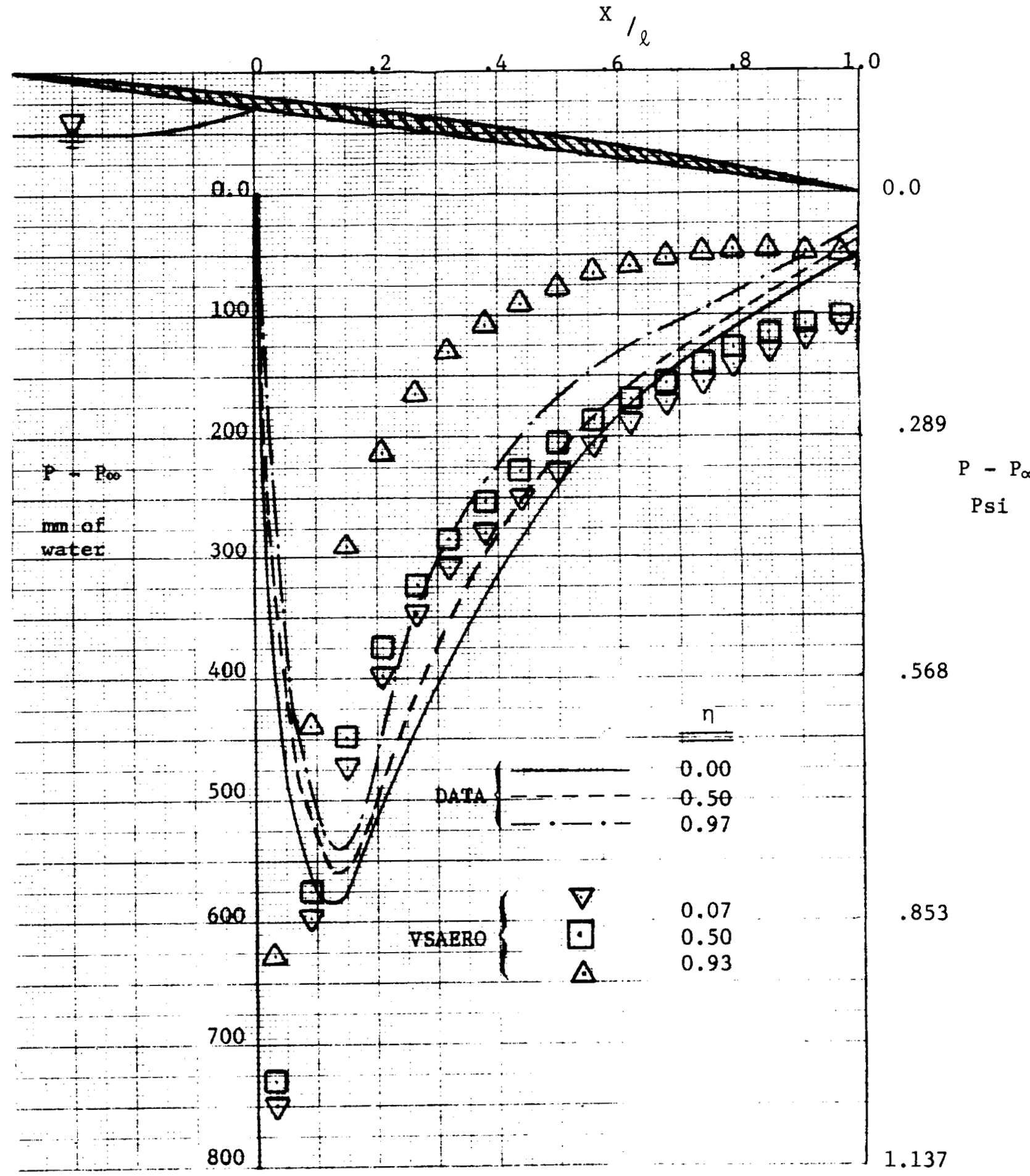

Figure 6. Computational and experimental hydrodynamic chordwise pressure distribution for a flat rectangular plate, $\alpha=8^{\circ}$,

$\mathrm{v}_{\infty}=19.7 \mathrm{ft} / \mathrm{s}$. 

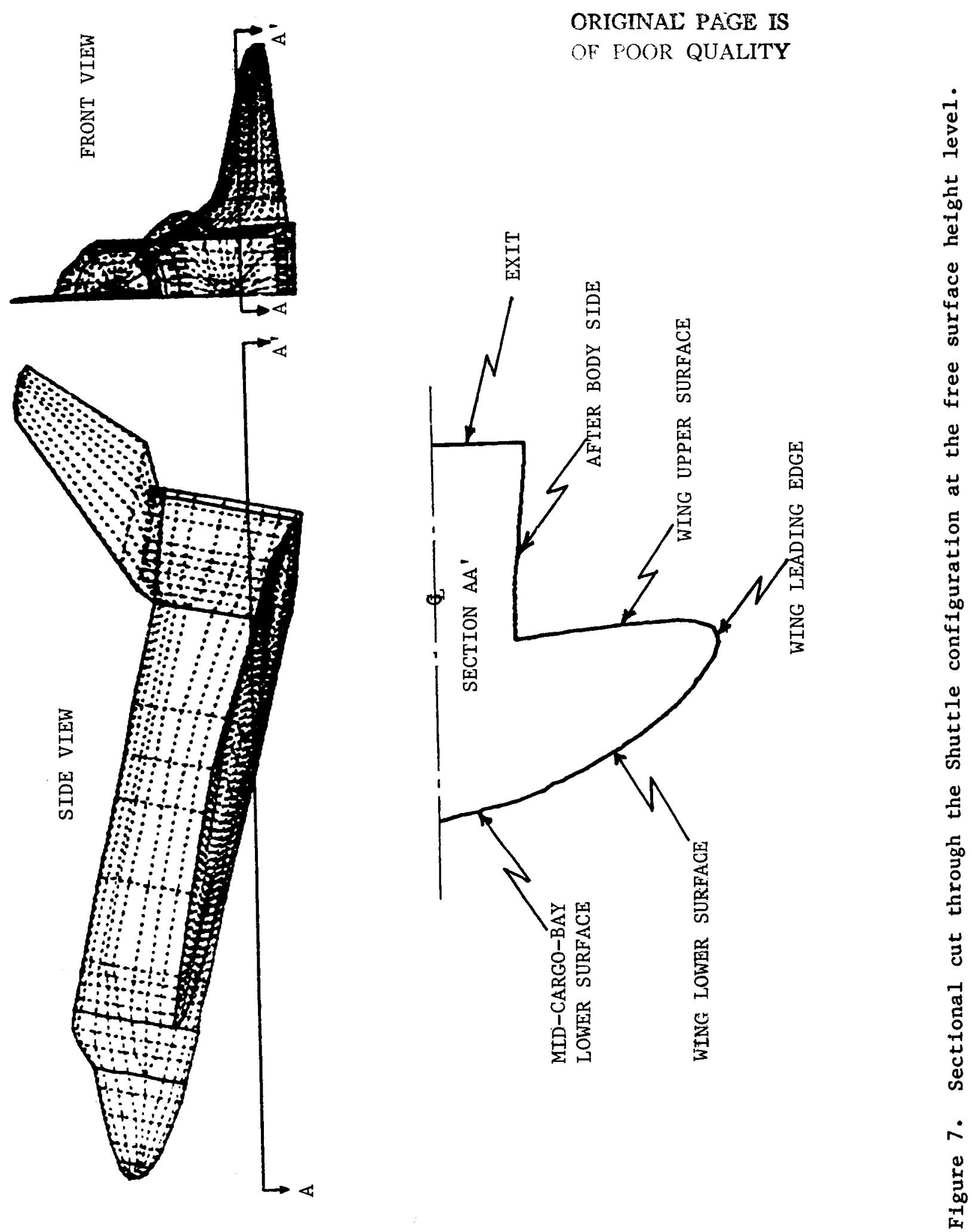


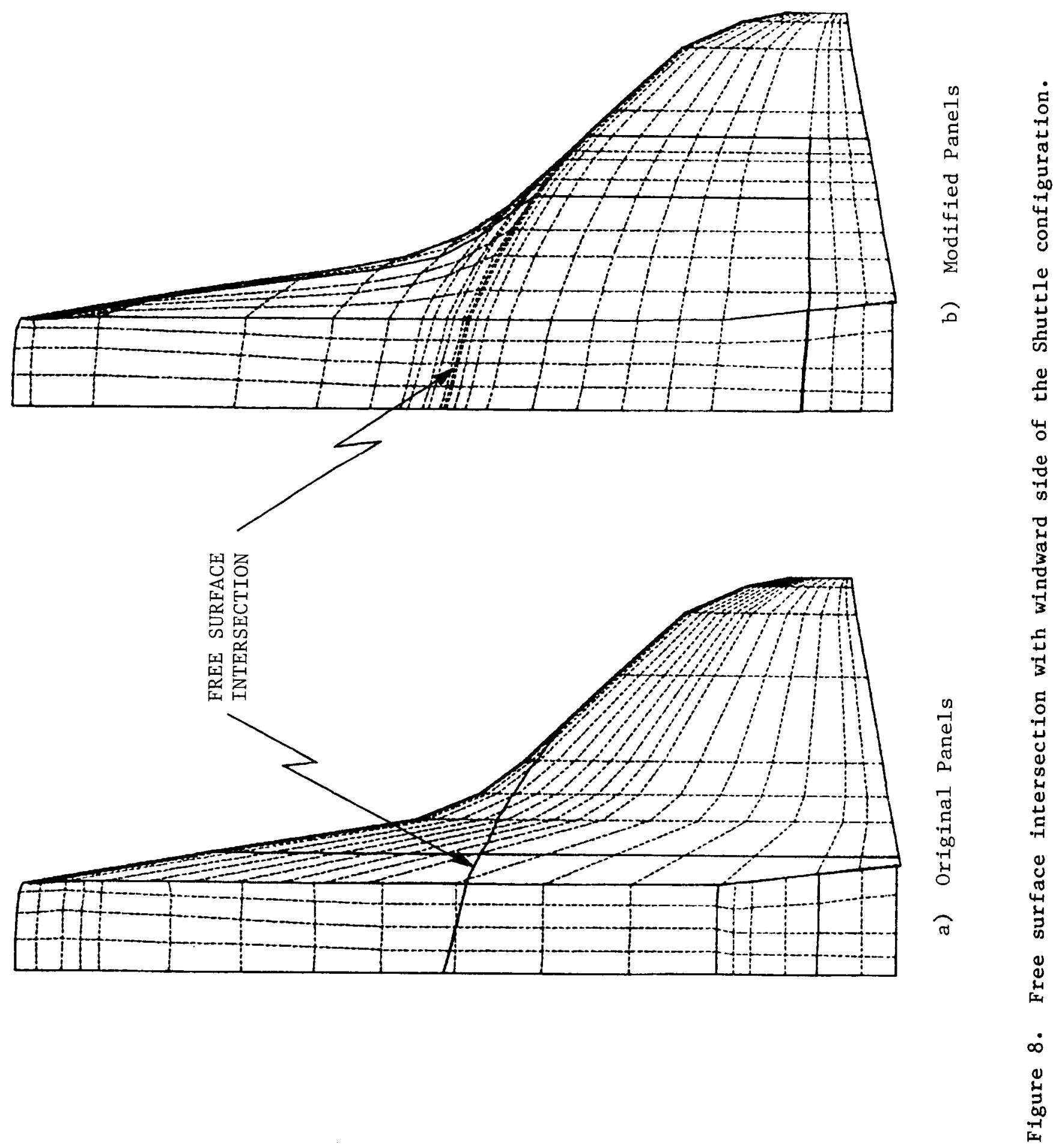

ORCLN "W....

OE POOR QUALITY 
ORIGINAL PAGL IS

DE POOR QUALITY

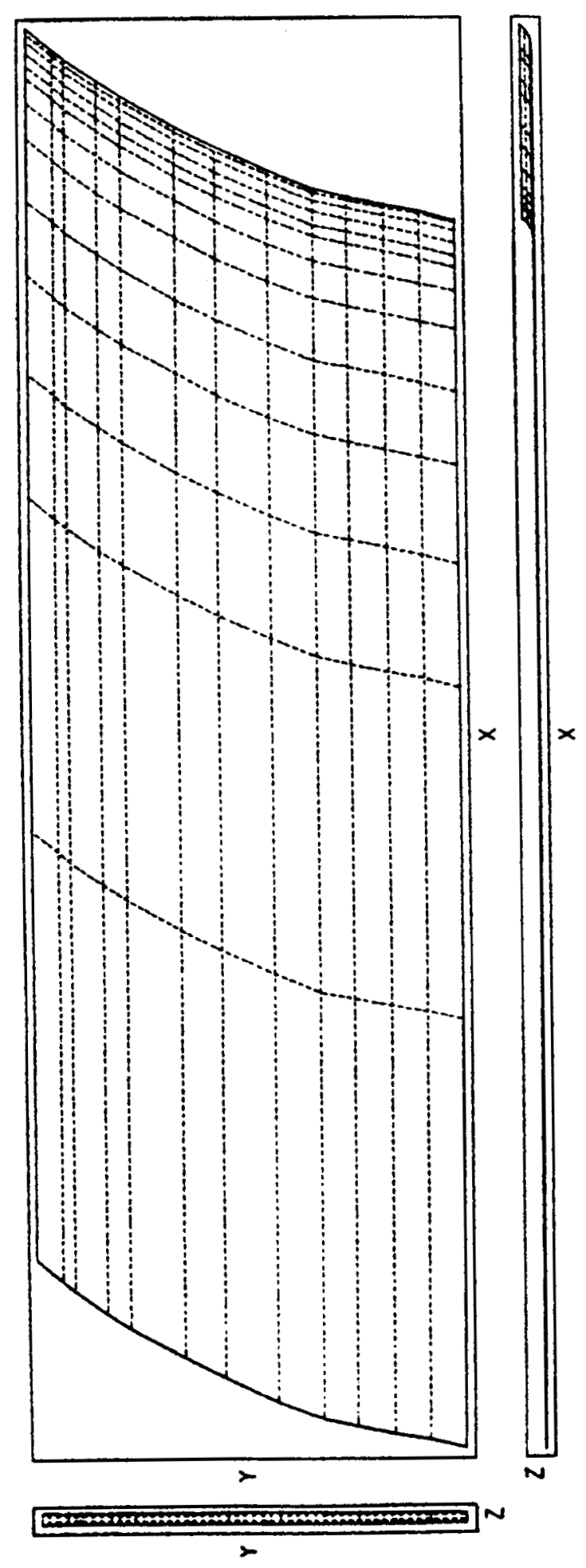

是 


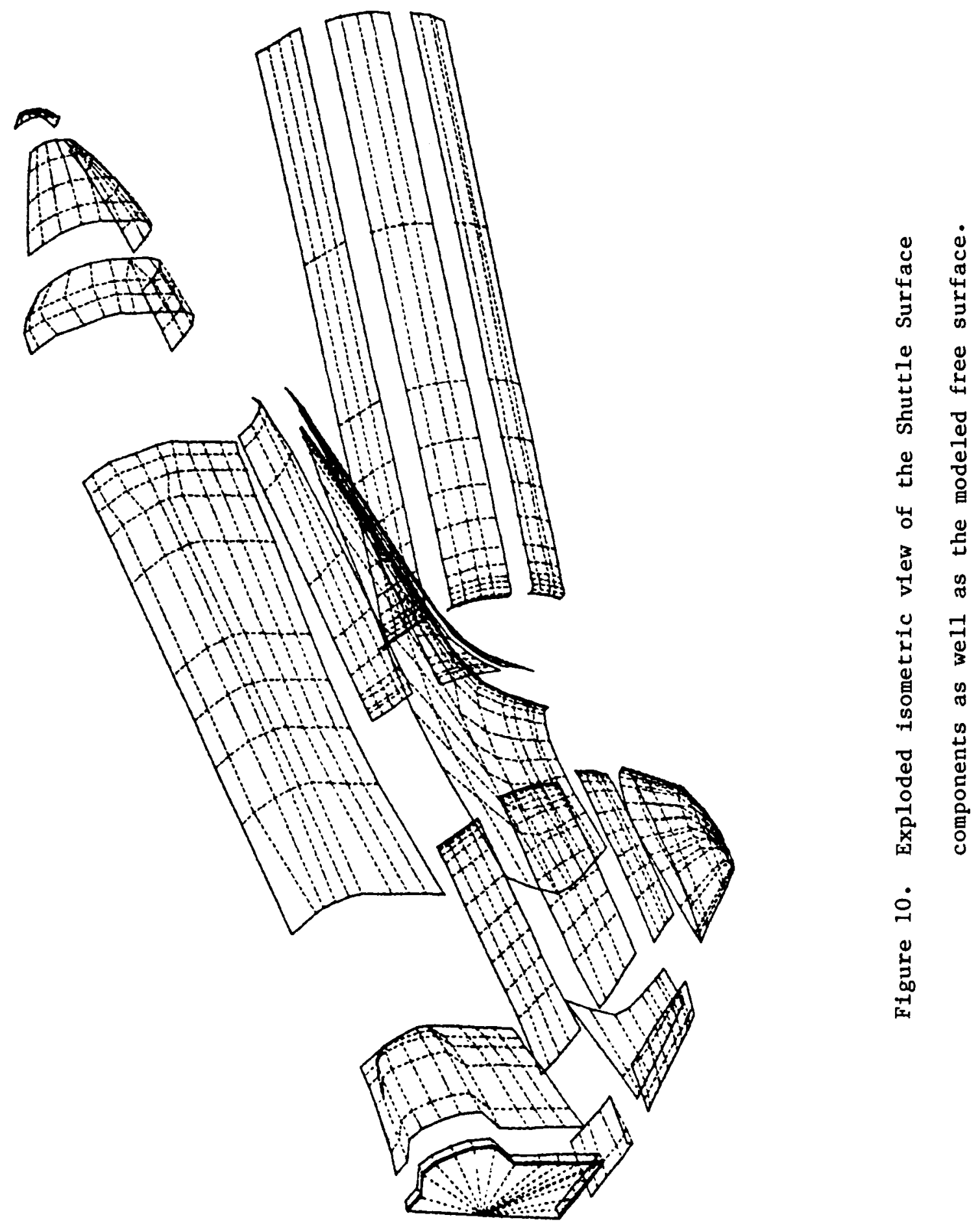


OXCRE
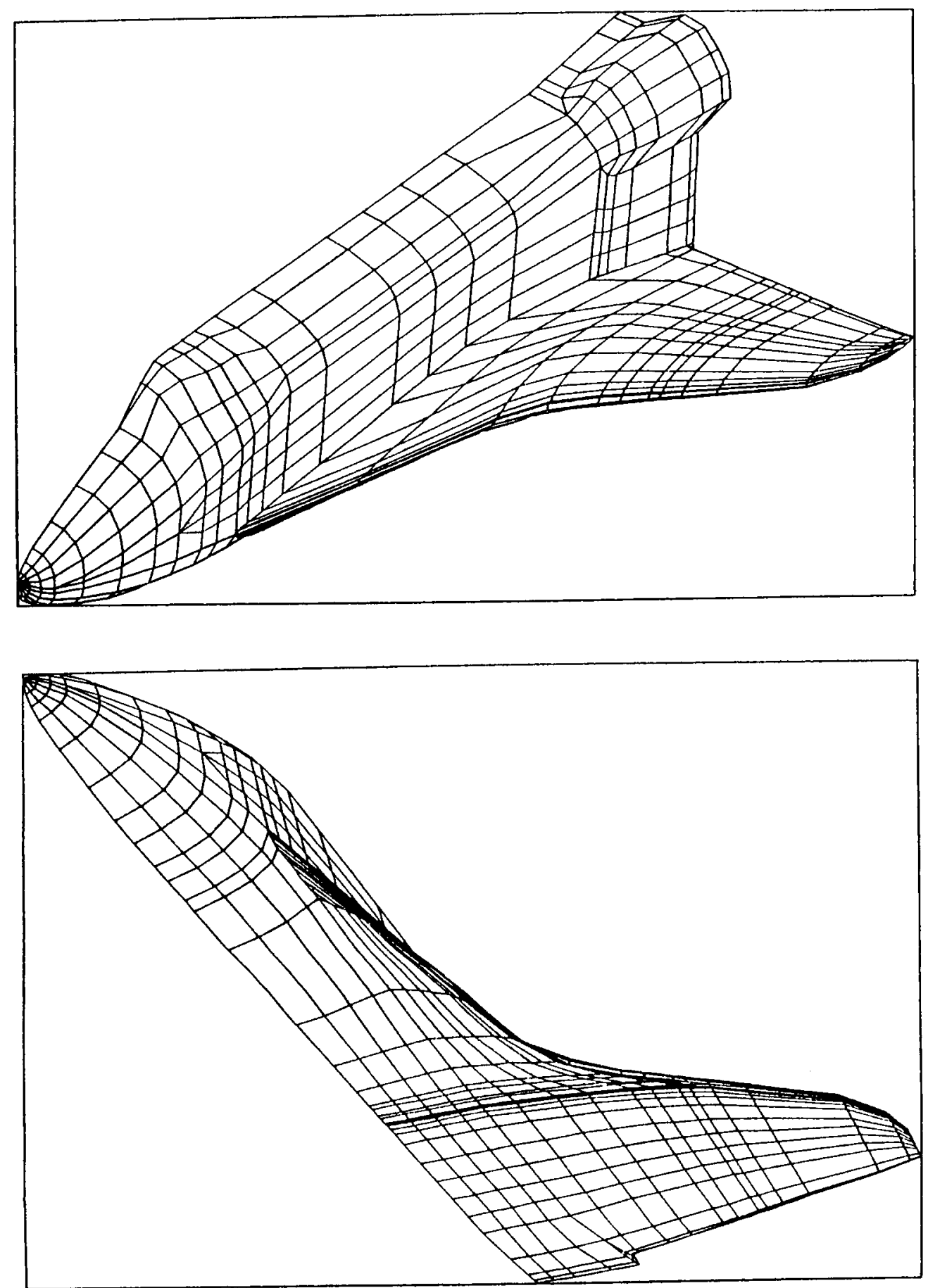

Figure 11. Surface panel representation of the Space Shuttle configuration used in VSAERO code from two difference viewpoints. 


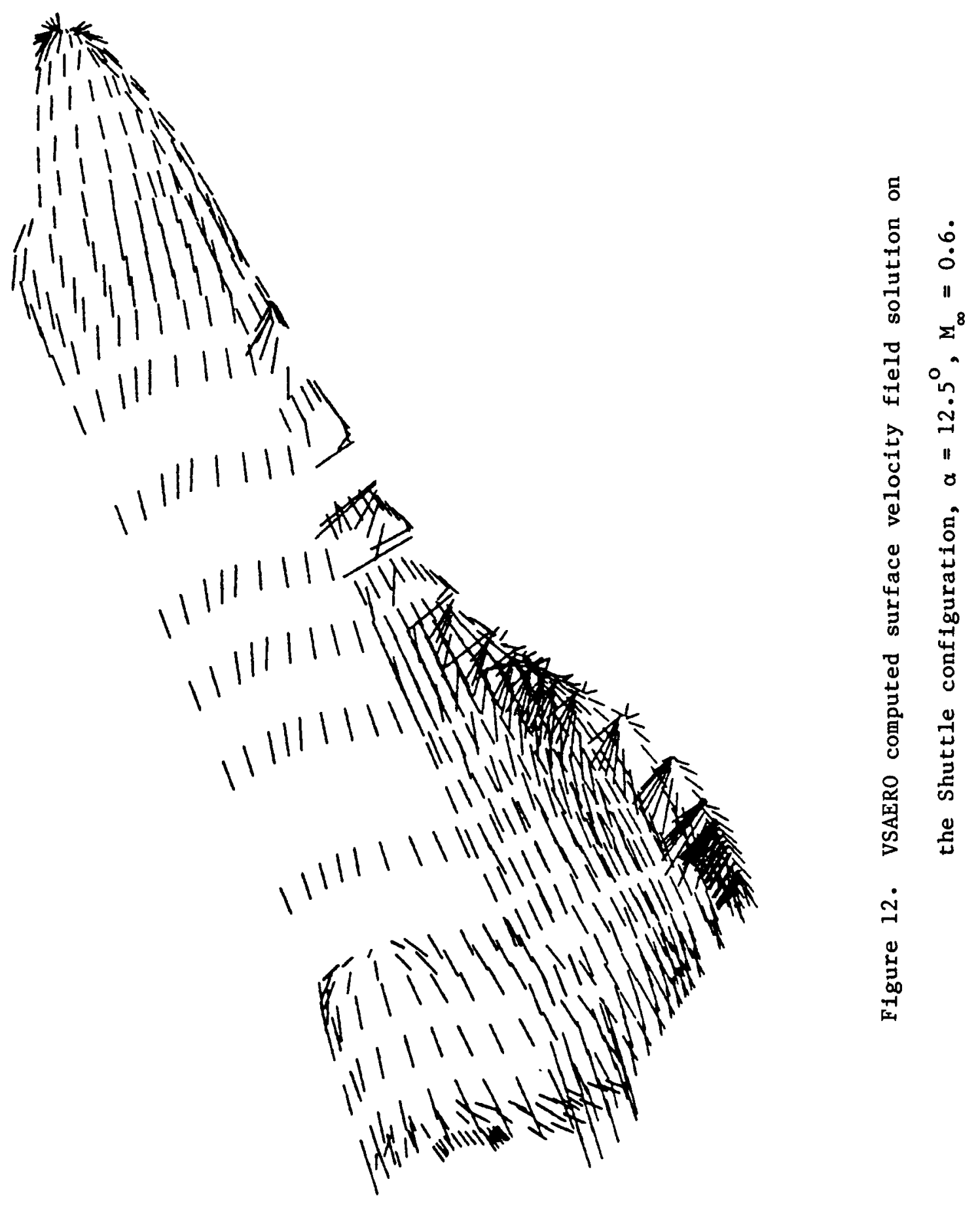




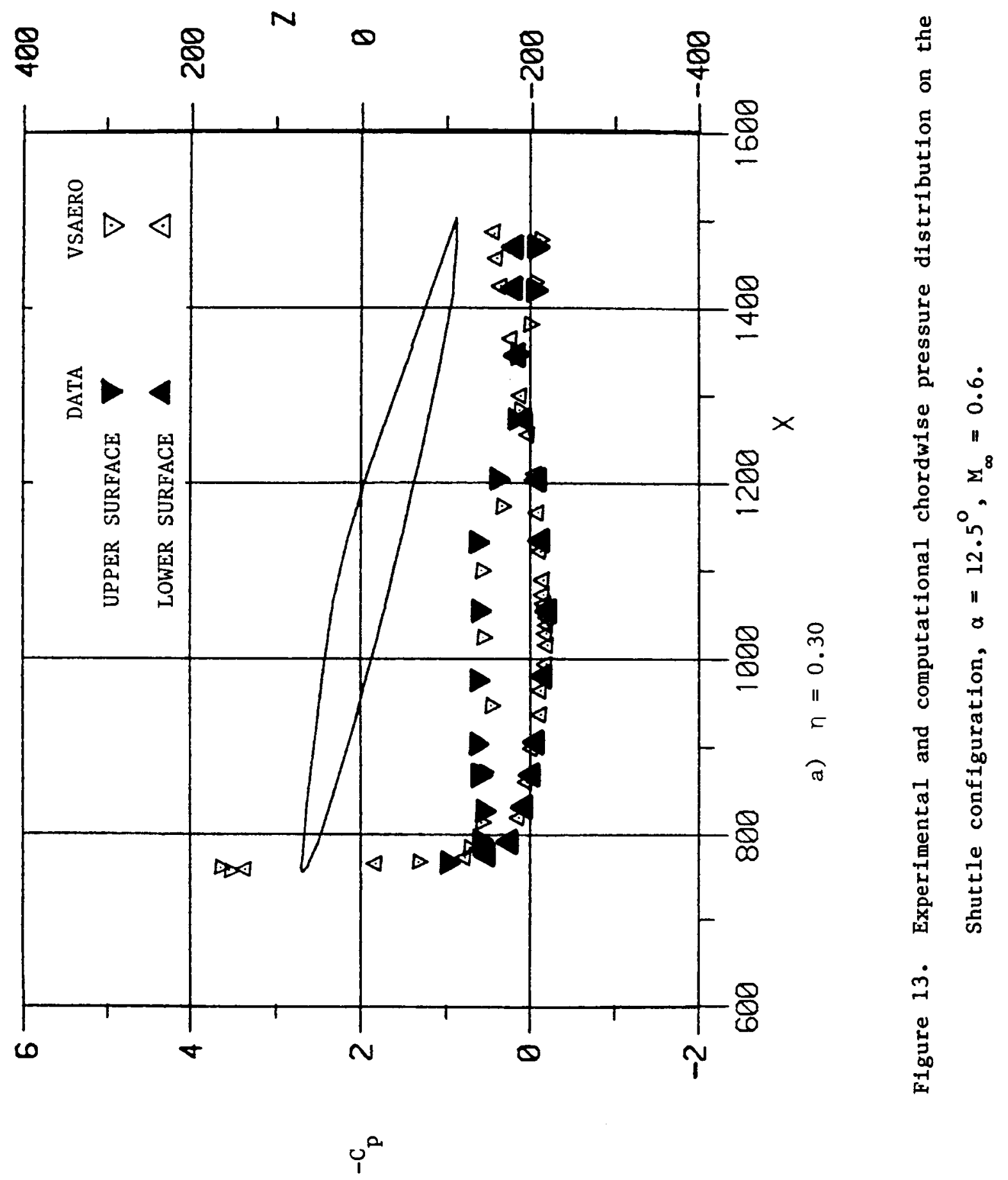




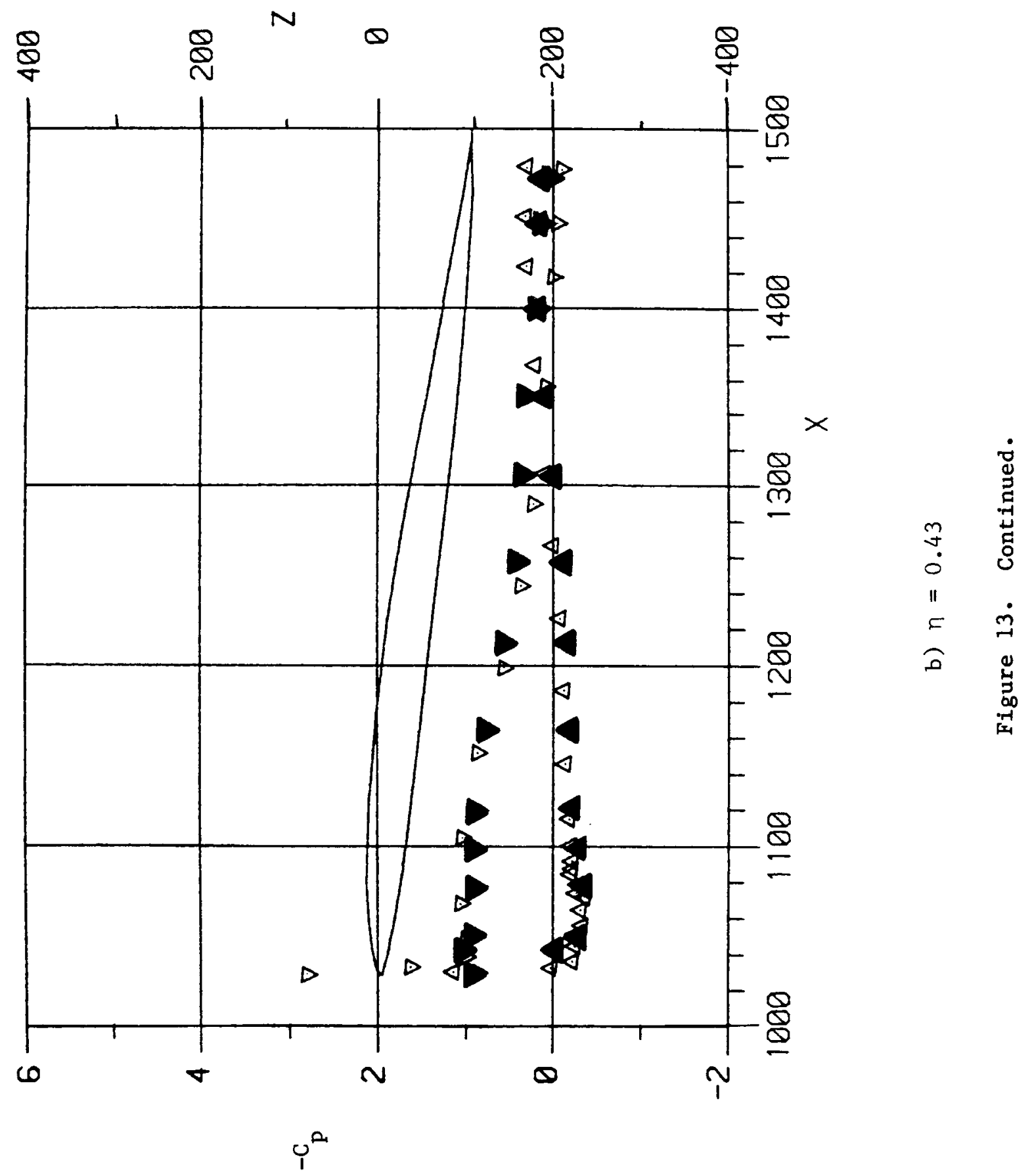




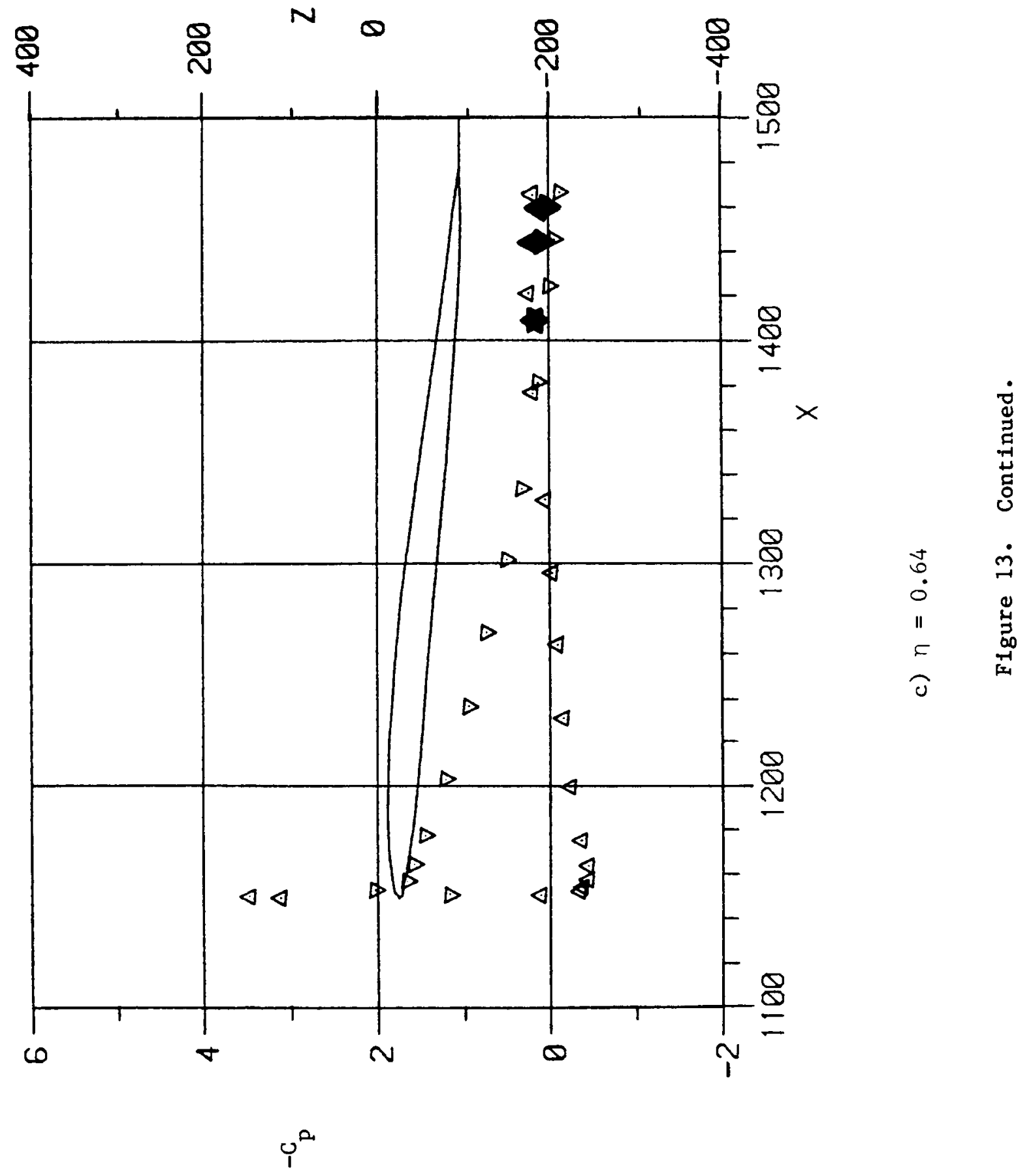




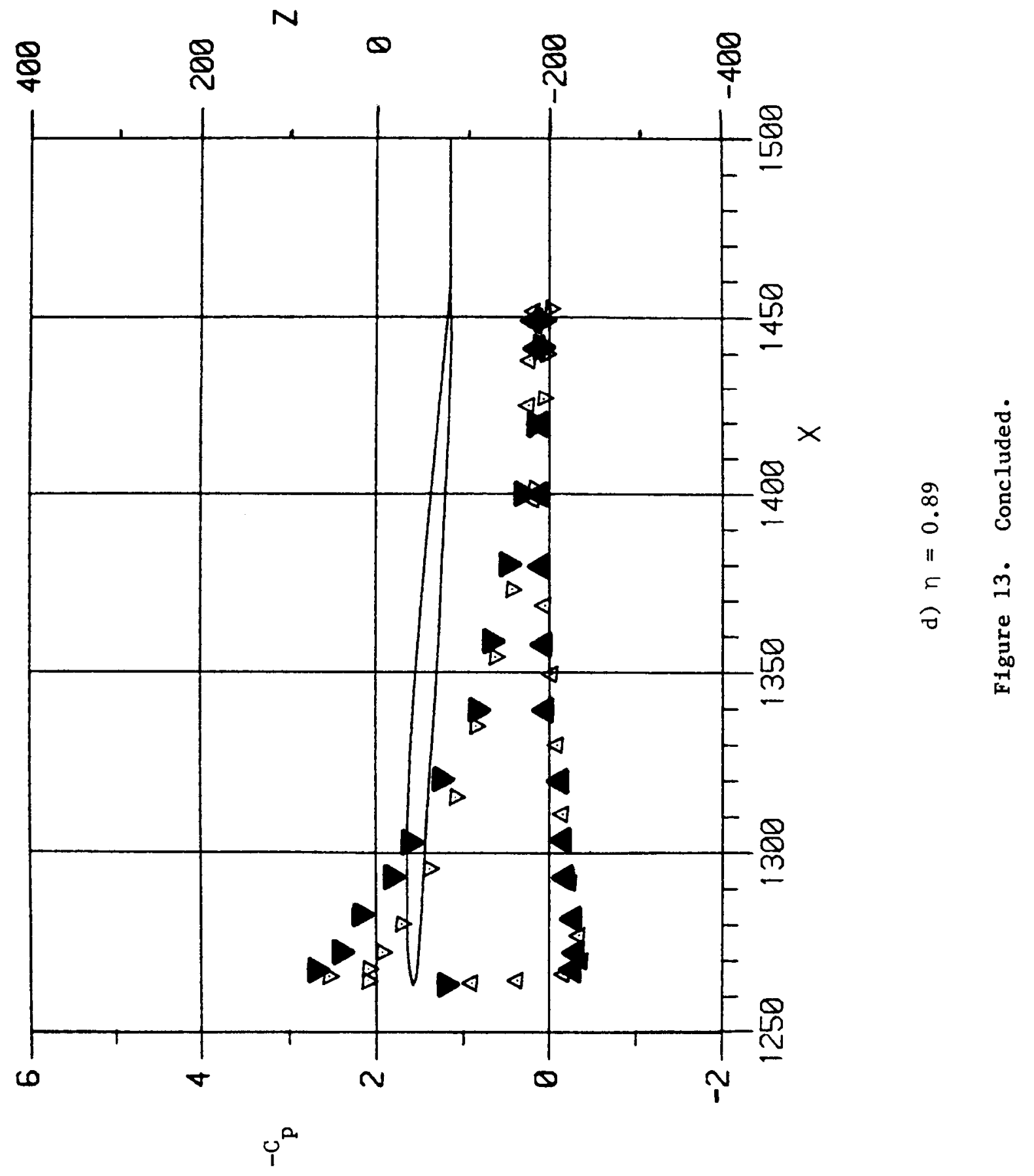


DRIGINAL PAGE IS

DOR POOR QUALITY
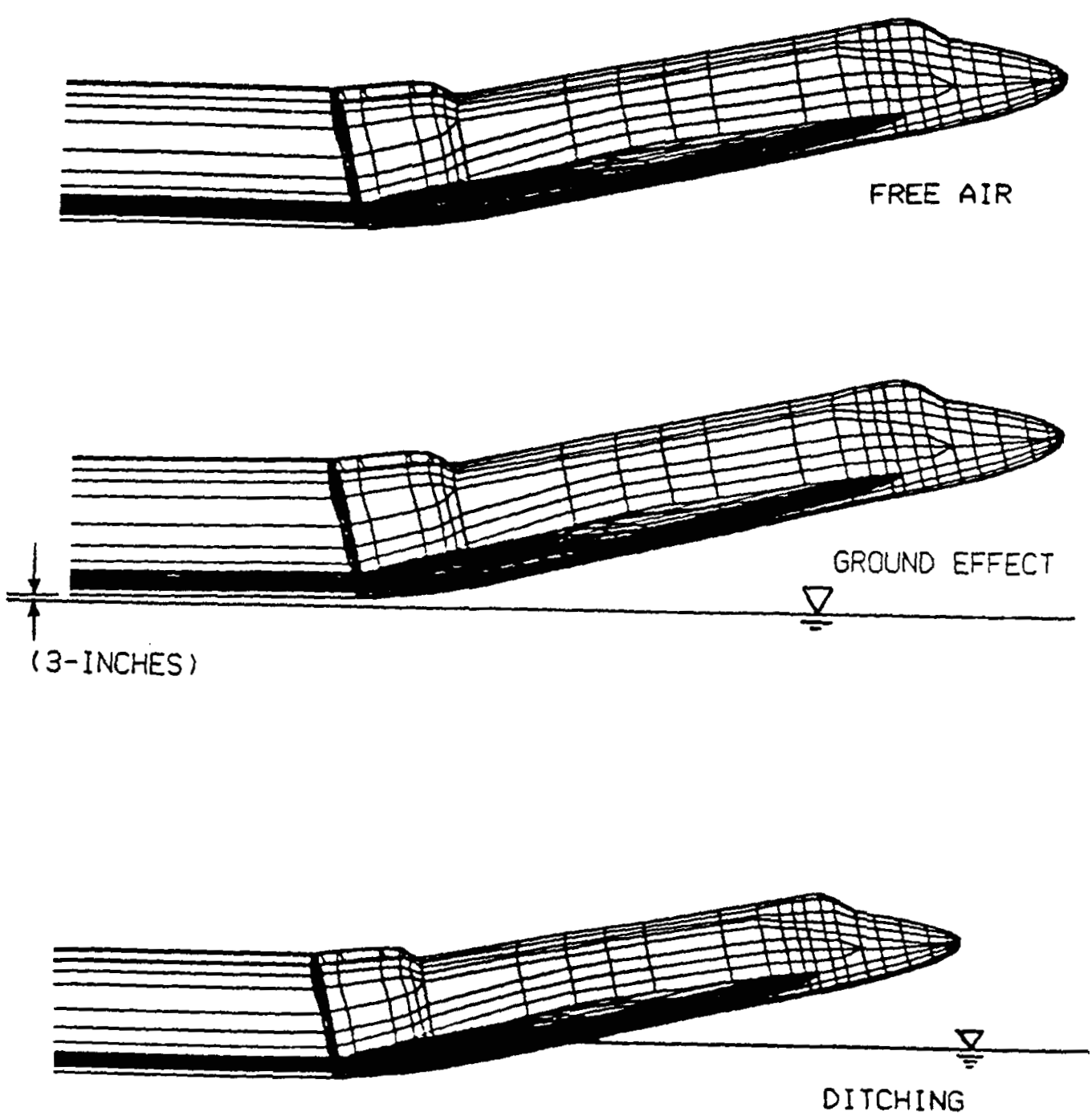

Figure 14. Side view illustration of the Shuttle configuration in free alr, ground vicinity and ditching. 

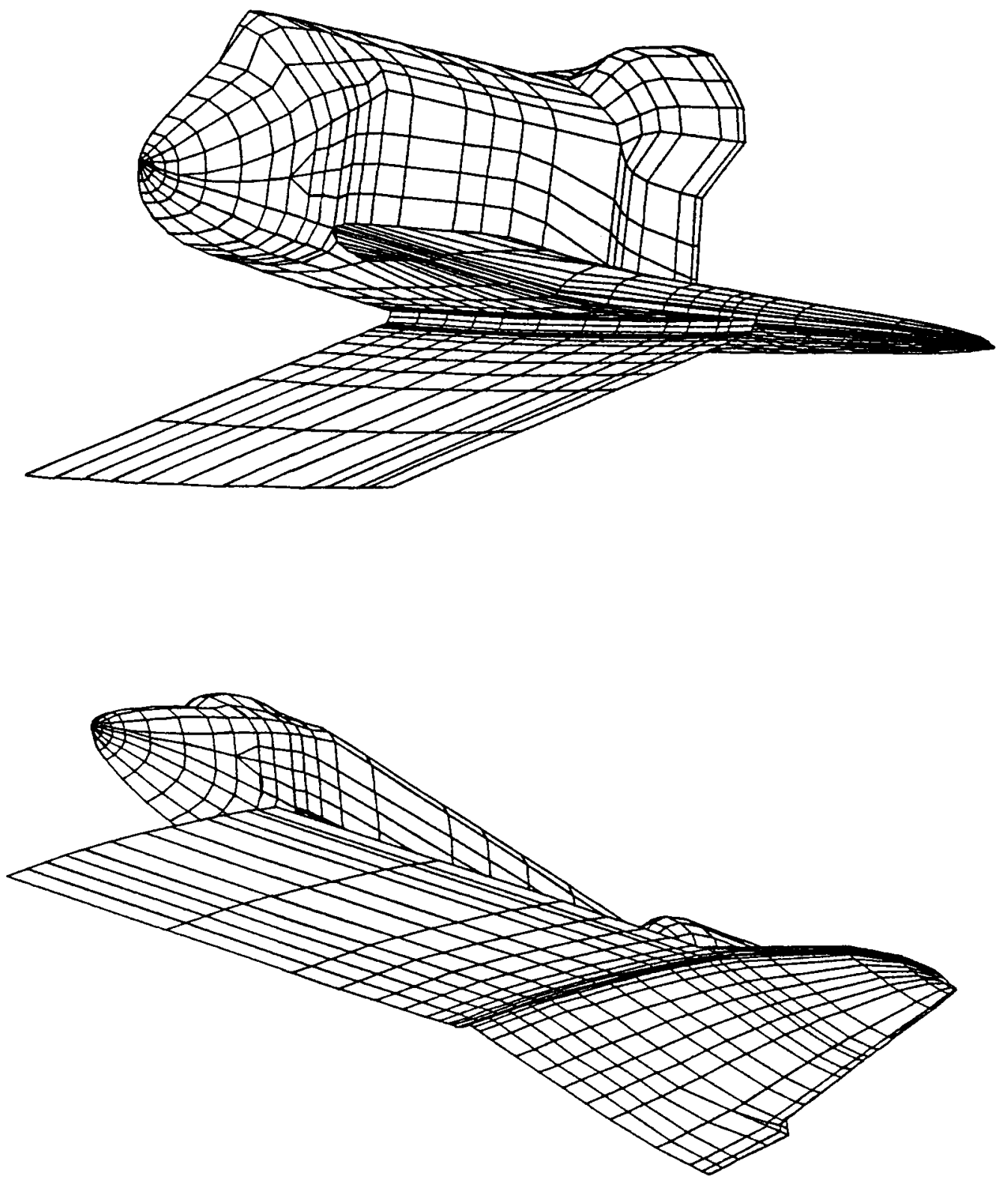

Figure 15. Two isometric views of the surface panels on the Shuttle configuration with modeled free surface. 


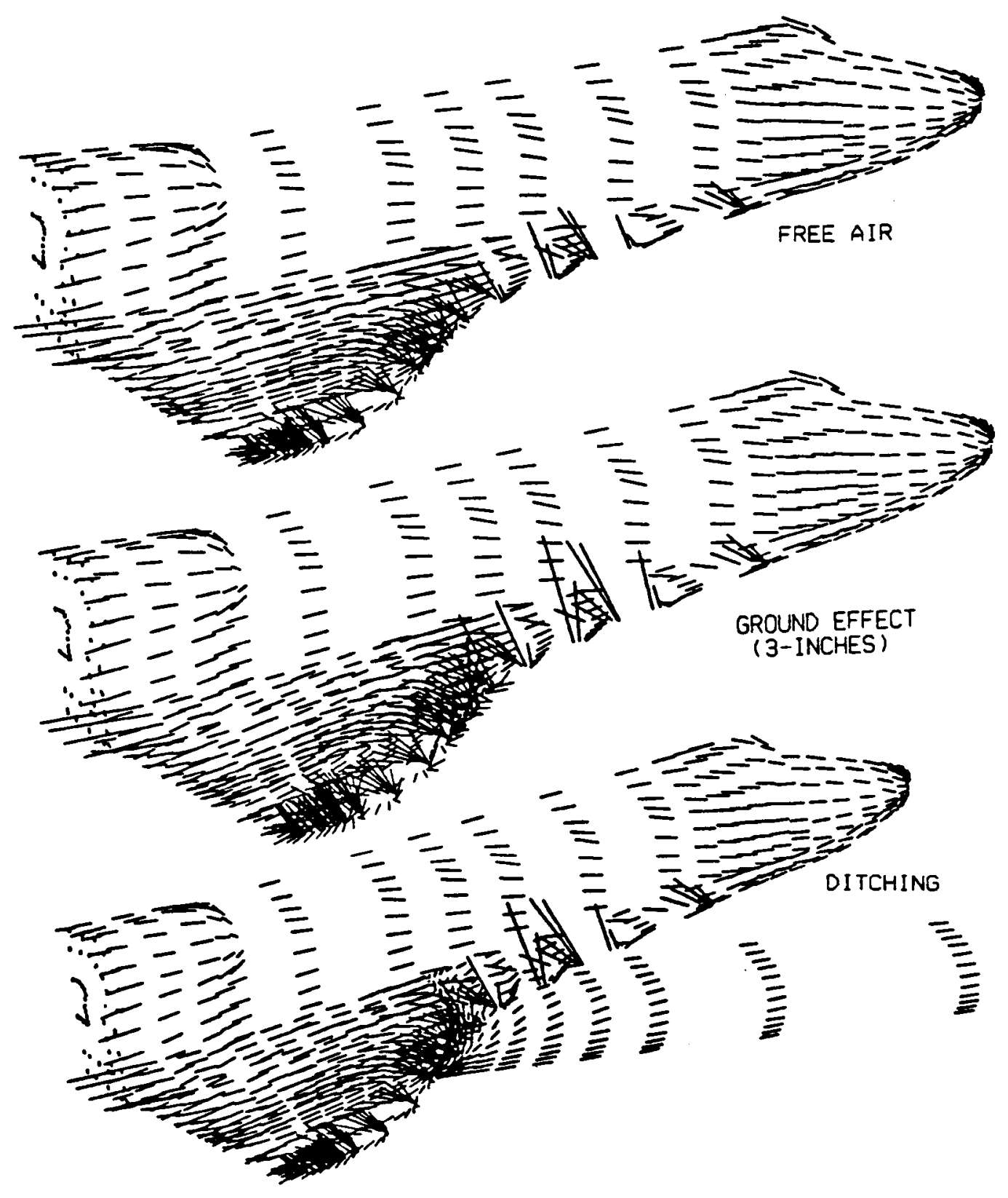

Figure 16. The Shuttle surface velocity field solutions for free air, ground vicinity, and ditching, $\alpha=12^{\circ}, M_{\infty}=0$. 


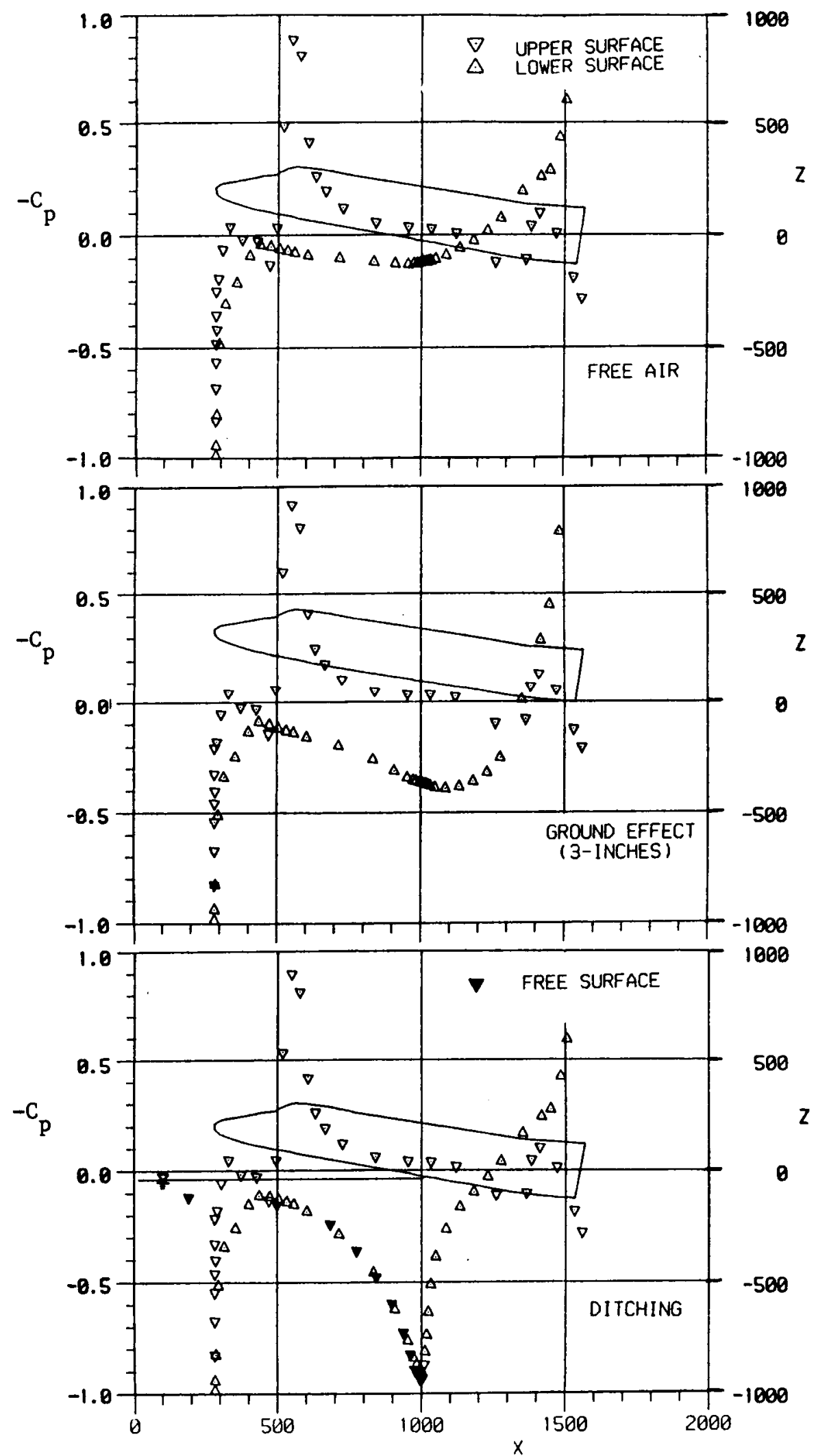

a) $\eta=.004$

Figure 17. The Shuttle streamwlse pressure distribution computed for free air, ground vicinity, and water ditching, $\alpha=12^{\circ}, M_{\infty}=0$. 




Figure 17. Continued. 


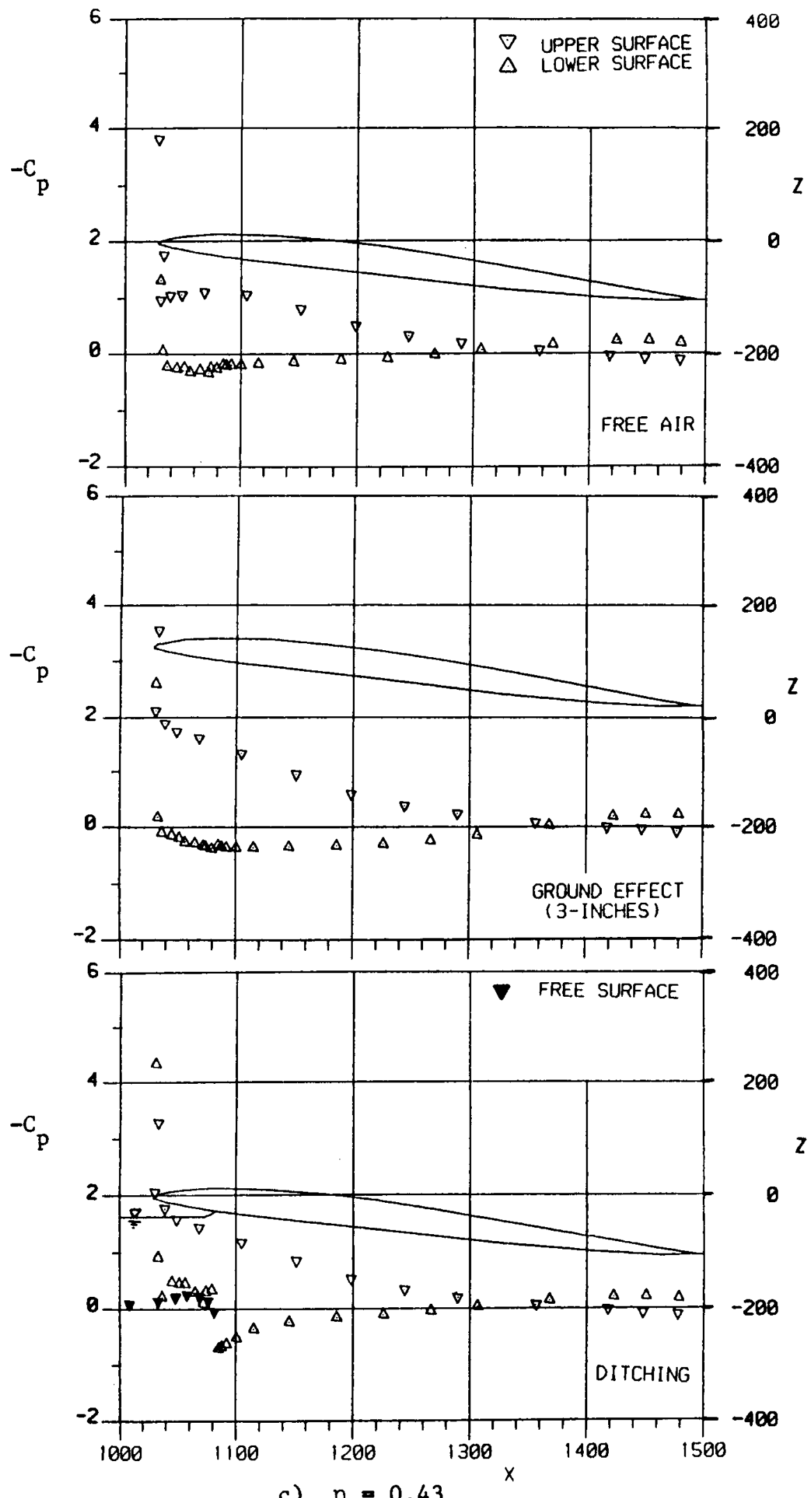

c) $n=0.43$

Figure 17. Continued. 


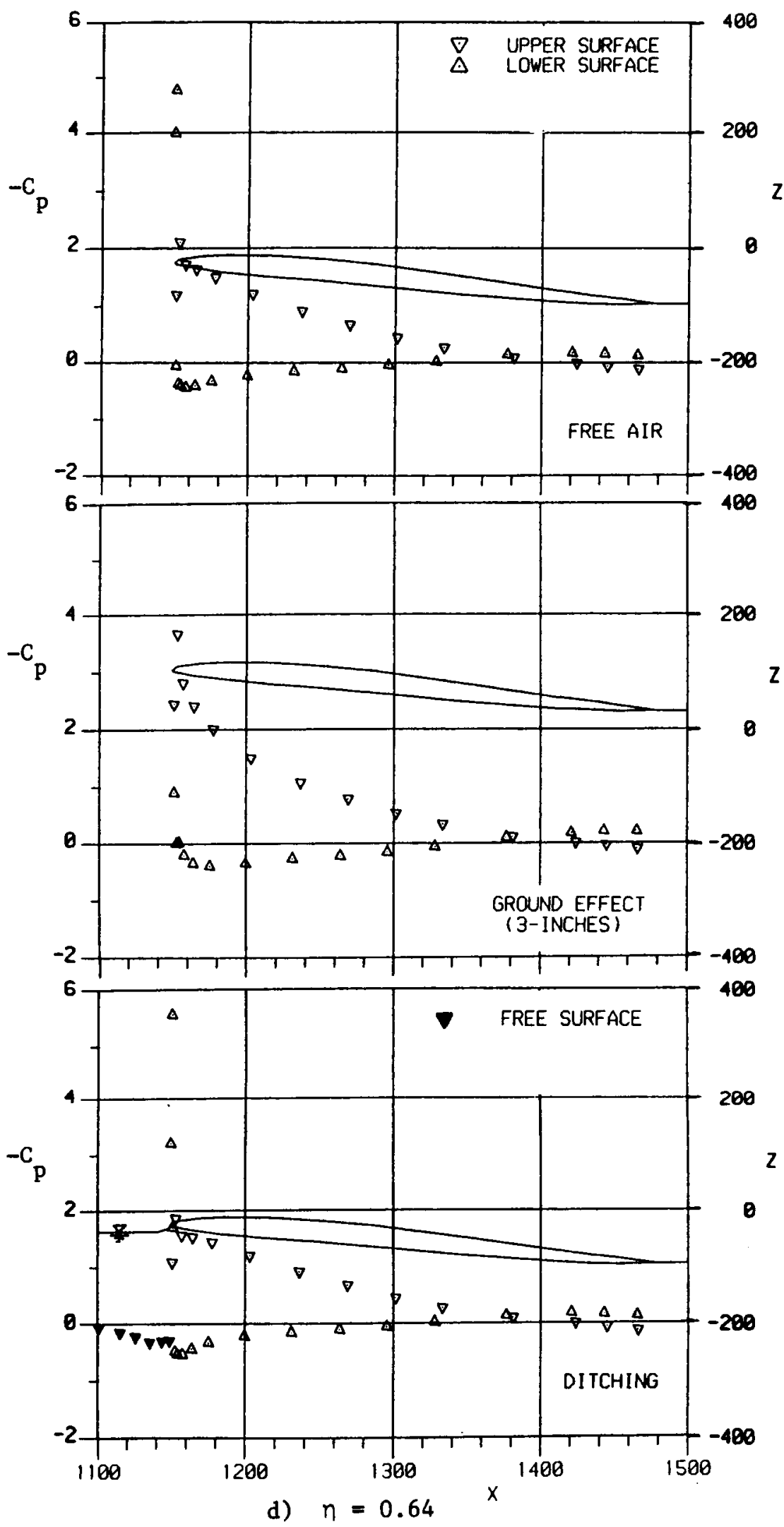

Figure 17. Continued. 


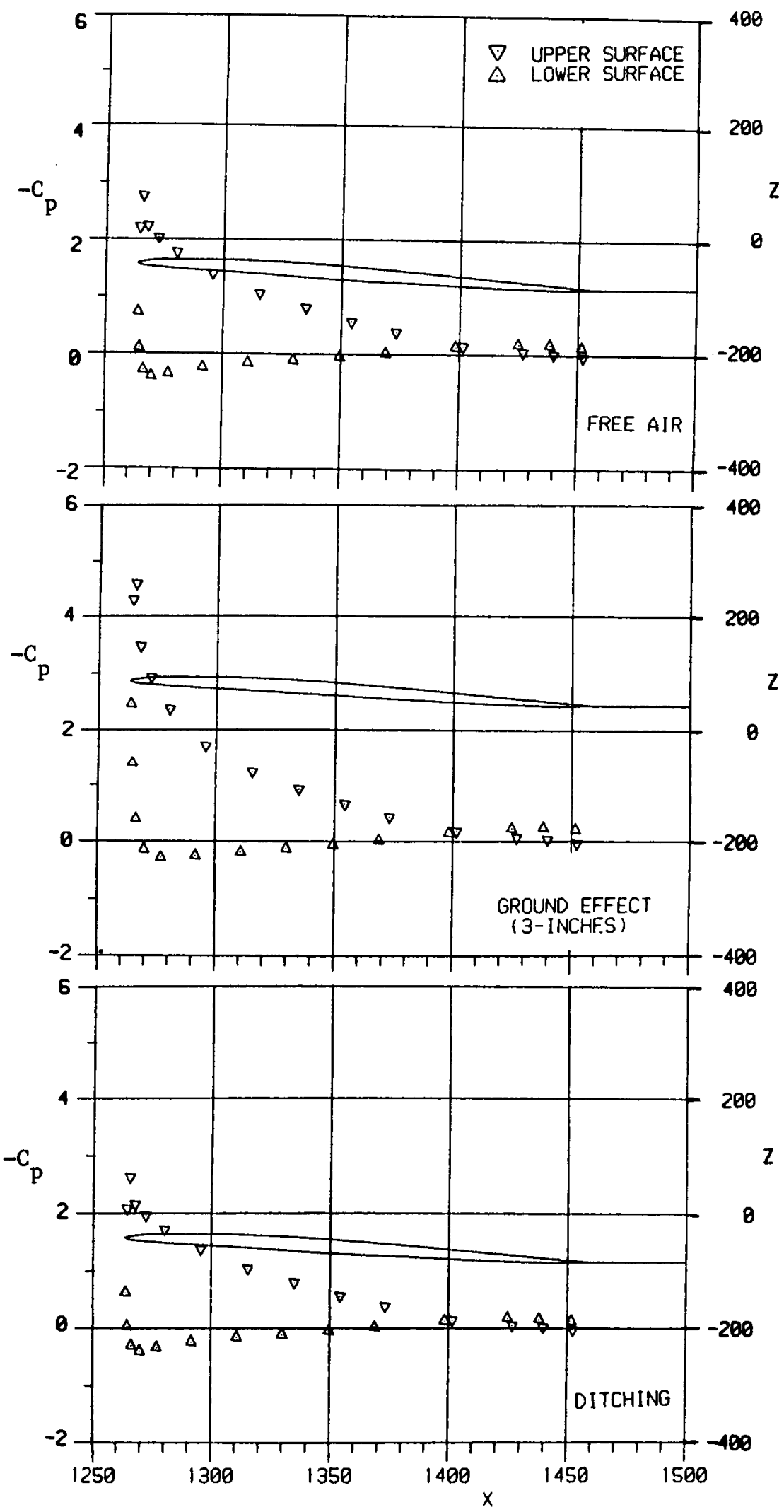

e) $n=0.89$

Figure 17. Concluded. 


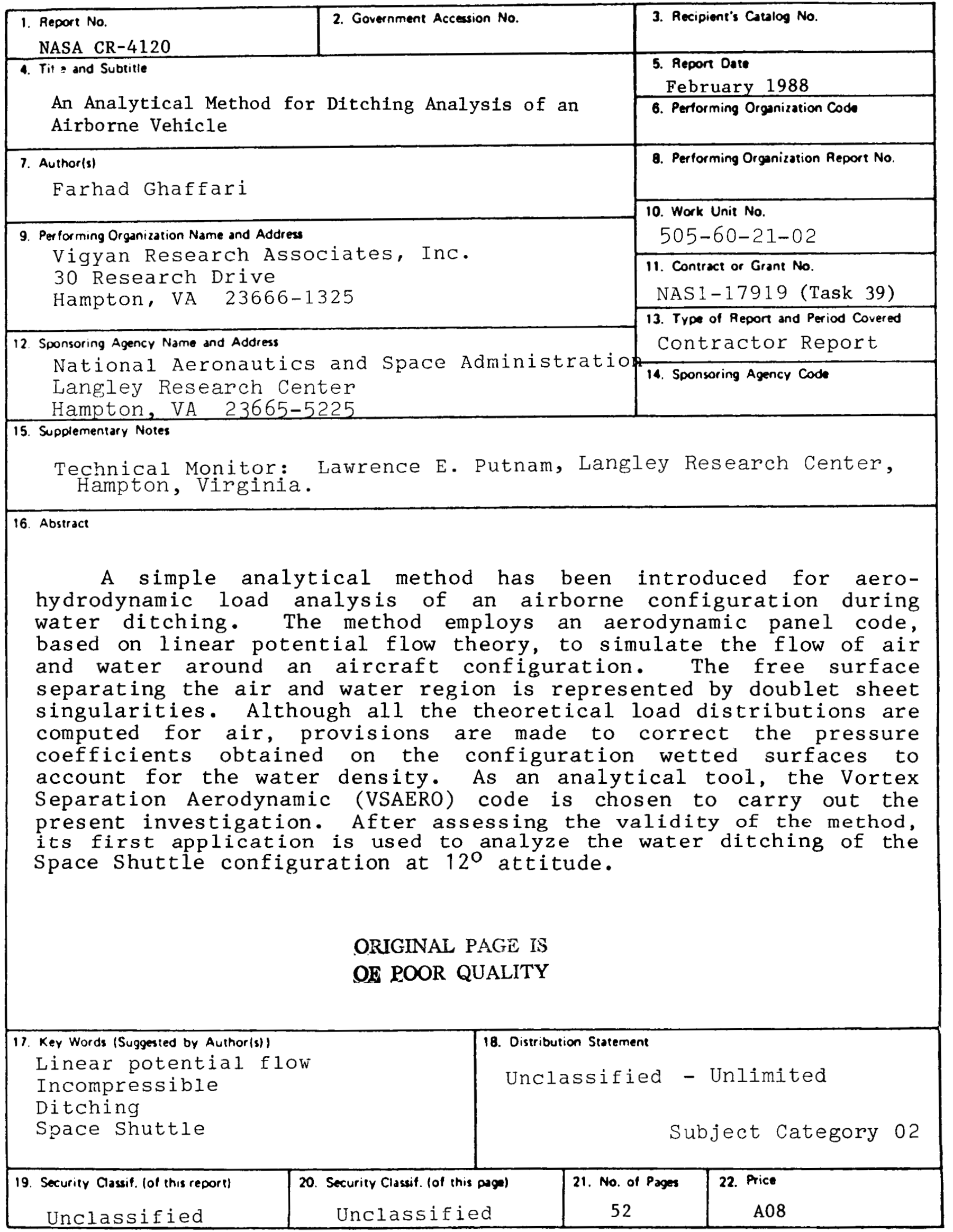

